RISK-BASED FAULT DIAGNOSIS AND SAFETY

MANAGEMENT FOR PROCESS SYSTEMS

HUIZHI BAO 




\title{
RISK-BASED FAULT DIAGNOSIS AND SAFETY MANAGEMENT FOR PROCESS SYSTEMS
}

\author{
by \\ Huizhi Bao \\ A thesis submitted to the School of Graduate Studies in partial fulfillment of \\ the requirements for the degree of

\section{Master of Engineering} \\ Faculty of Engineering and Applied Science \\ Memorial University of Newfoundland \\ March, 2010
}

St. John's

Newfoundland 


\begin{abstract}
Today, plants in ehemical and process industry are becoming larger and more complex. Corollary of this trend implies that each hour of down time is more expensive. As industrial systems enlarge, the total amount of energy and material being handled increases, making fault diagnosis and safety management considerably important both from the viewpoint of process safety as well as economic loss. Therefore, secking an effective approach to perform fault diagnosis and implement safety management is important and imperative. An imovative methodology of risk-based SPC fault diagnosis and its integration with Safety Instrumented System (SIS) is proposed in this thesis to assure the process safety:
\end{abstract}

Unlike any existing fault diagnosis and safety management approaches, the proposed methodology pioneers a brand new pathway for the fault diagnosis and safety management in process industry. This proposed methodology neither depends on any process model as model-based methods, nor depends on large amount of historical process data as conventional process history based method. Control chart technique is used to distinguish abnormal situation from normal operation based on three-sigma rule and linear trend forecast. Time series and moving average techniques are used to perform real time moaitoring and noise filtering in fault diagnosis process. Furthermore, risk indicators are used to identify and determine potential fault(s) to minimize the number of false alarms.

The proposed methodology of risk-based SPC fuult diagnosis and its integration with safety instrumented systems is implemented using $\mathrm{G} 2$ development environment. To test and verify this methodology, a tank filling system and a steam power plant system with SIS1s and SIS2s are developed in G2 environment. A technique breakthrough, from univariate monitoring to multivariate monitoring for SPC fault diagnosis has been made in the verification in the steam power plant system. 


\section{Acknowledgements}

As a person who desires to dedicate herself to a researeh which is her dream in ber life, the biggest wish for her is to have an opportunity to pursue this dream and make it true. The School of Graduate Studies of Memorial University of Newfoundland provides this opportunity to the author, so please allow the author to express ber sinecre appreciation to him first.

Dr. Faisal Khan and Dr. Tariq Iqbal, two of the most outstanding professors in the Faculty of Engineering and Applied Science at Memorial University of Newfoundland, provided the author with detailed guidance and also financial support for her research. Herein, please aceept the thankfulness from the author's heart to them.

Appreciations are also shown to Dr. Yanjun Chang, Mr. Cen Nan and all the friends who have ever helped the author in her rescarch and her life.

Thanks the author's family, without the understanding and support from them, the author would not bave the study opportunity in Memorial University of Newfoundland. 
Table of Contents

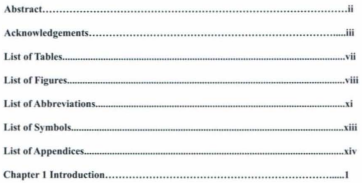

1.1 Safety Instrumented System....................................................

1.1.1 Process Control System and SIS .......................... 3

1.1.2 Risk and Risk Reduction Methods.............................................. 5

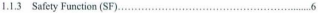

1.2 Safety Analysis ................................................................. 8

1.2.1 Risk Classification...........................................................8

1.2 .2 Risk Reduction Terms and Equations.................................... 9

1.23 Safety Integrity Level (SIL) ................................................10

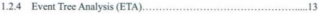

1.3 Statistical Process Control.............................................................. 15

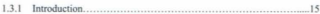

1.3 .2 Control Chart.......................... 16

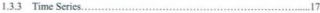

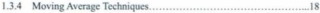

1.4 Objectives of This Research.

15 Organization of This Thesis.................................... 26 
Chapter 2 Methodology of Risk-based SPC Fault Diagnosis and Safety Management for Process System.

2.1 Review of Existing Fault Diagnosis Methods......................................27

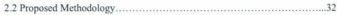

2.3 Verification of Proposed Fault Diagnosis Methodology .........................35

2.3.1 Fault Diagnosis Principle...................................................37

2.3.2 SPC Fault Diagnosis.................................................................38

2.3.3 Risk-based SPC Fault Diagnosis................................................41

2.4 G2 Development Environment........................................................

Chapter 3 Implementation and Verification of the Proposed Methodology in G2

Development Eavironment - Tank Filling System....................51

3.1 Requirements to the Tank Filling System...........................................51

3.2 Deterministic Development Stage...............................................53

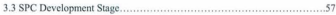

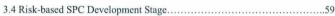

3.4.1 Characteristic Functions and Faalt Definition ................................60 60

3.4.2 The Development of SIS1 ......................................................... 64

3.4.3 The Development of SIS2 ................................................67

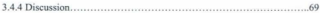

3.4.5 Comparison with Cen Nan's Work..................................... 70

Chapter 4 Implementation and Verification of the Proposed Methodology in G2 Development Environment - Steam Power Plant System............ 73

4.1 Requirements to the Steam Power Plant System..................................74

4.2 Console Construction in G2 Environment......................................77

4.3 System Modeling ..................................................................... 
4.4 The Implementation of the Proposed Methodology................................81

4.4.1 SPC Development Stage.....................................................81

4.4.2 Risk-based SPC Development Stage.......................................87

4.4.2.1 Characteristic Functions and Fault Definition.....................87

4.4.2.2 The Development of SIS1 \& SIS2 ................................90

4,4,2.3 Comparison with Traditional Approach..........................95

Chapter 5 Characteristics of the Proposed Methodology.............................99

Chapter 6 Conclusion and Future Work........................................103

6,1 Conclusion.................................................................................... 103

6.2 Future Work..........................................................................106

References....................................................................................107

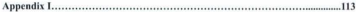

Appendix II........................................................................115 


\section{List of Tables}

Table 1: Risk Classification of Accidents: Table B1 of IEC 61508-5 ................. 8

Table 2: Risk Classification of Accidents: Trial Values.......................................9

Table 3: Definitions of SIL.5 for demand mode of operation from IEC 61511-1.........12

Table 4: Steam Pressure Data for the Steam Power Plant (Nomal Situation)............ 35

Table 5: Steam Pressure Data for the Steam Power Plant (Abnormal Situation)........35

Table 6: Moving Average Stean Pressure Data for the Steam Power Plant System

(Normal Situation).........................................................................36

Table 7: Moving Average Steam Pressure Data for the Steam Power Plant System

(Abnormal Situation) .

Table 8 Safety Integrity Level (SIL) Evaluation to the Tank Filling System............56

Table 9; Comparison to Cen Nan's Work for the Tank Filling System...................72

Table 10: Comparison between the KBRT Approach and the Risk-based SPC Approach

98

Table 11: Risk Culculation for Tank Filling System ....................................113

Table 12: Risk Calculation for Steam Power Plant System................................115 


\section{List of Figures}

Fig. 1 Main Parts of a Safety Instrumented System....................................... 3

Fig. 2 Separation of BPCS and Protection System........................................ 3

Fig. 3 Basic SIS Layout......................................................................4

Fig. 4 Safety Protective Layers............................................................ 6

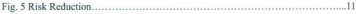

Fig. 6 Determination of SIL .................................................................. 12

Fig, 7 An Example of Event Tree Analysis:...............................................14

Fig. 8 An Example of Control Chart............................................................16

Fig. 9 Time Series: random data plus trend, with best-fit line and different smoothings

Fig, 10 An example of Moving Average of Stock Price Chart..............................19

Fig. 11 WMA Weights...................................................................... 22

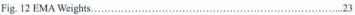

Fig. 13 Classification of Diagnostic Algorithms (Venkatasubramanian et al., 2003)

Fig. 14 Pathway of Proposed Methodology in the Classification of Diagnostic Algorithms

Fig. 15 Methodology of the Risk-based Fault Diagnosis and Safety Management for

Process Systems.................................................................................. 34

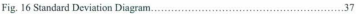

Fig. 17 Normality Test for Steam Pressure Data in Normal Situation..................... 38

Fig. 18 Normality Test for Steam Pressure Data in Abnormal Situation...............39

Fig, 19 Line Chart for Moving Average Steam Pressure Data in Normal Situation... 40

Fig. 20 Line Chart for Moving Average Steam Pressure Data in Abnormal Situation

Fig. 21 Error Function ................................................................4 43

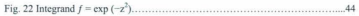


Fig. $23 \operatorname{erf}(z)$ 44

Fig. 24 G2 Platform from Gensysm Corporation...........................................48 48

Fig. 25 Console of the Tank Level Monitor with BPCS.....................................53

Fig. 26 Console of the Tank Level Monitor with BPCS \& SIS1 ............................54

Fig. 27 Console of the Tank Level Monitor with BPCS \& SISI \& SIS2 ................55

Fig. 28 Control Chart for the Tank Filling System.......................................58

Fig, 29 Risk-based SPC Fault Diagnosis and SISs for Tank Filling System............60

Fig. 30 An Example of Rule Definition in Tank Filling System..........................62

Fig. 31 Data Points in Time Order...........................................................63

Fig. 32 Risk-based Tank Level Control Chart .............................................64

Fig. 33 Risk-based Tank Level Trend Chart-SIS1 ............................................65

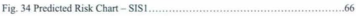

Fig. 35 Risk-based Tank Level Trend Chart-SIS2 _..................................68

Fig. 36 Predicted Risk Chart -SIS2 .

Fig. 37 Risk-based Tank Level Trend Chart - SIS2, .................................70

Fig. 38 Console of the Tank Filling System in Cen Nan's Work........................71

Fig. 39 Steam Power Plant in Thermodynamics and Fluids Lab. ..........................74

Fig. 40 Schematic Diagram of the Steam Power Plant............................................75

Fig. 41 Console of the Steam Power Plant System......................................... 78

Fig. 42 Historical Data Chart for the Boiler Steam Pressure ............................. 79

Fig. 43 Characteristics of an Under-damped Response..................................80 80

Fig. 44 Control Chart of the Steam Pressure in Steam Power Plant System.............82 82

Fig. 45 Control Chart of the Steam Pressure in Steam Power Plant System (Normal

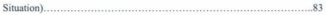

Fig. 46 Control Chart of the Steam Pressure in Steam Power Plant System (Abnormal

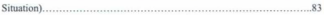

Fig. 47 Cen Nan's Steam Power Plant System + Huizhi Bao's Diagnosis Module... 84

Fig. 48 Assumptions in Cen Nan's Steam Power Plant System ................................85

Fig. 49 False Alarm in Cen Nan's Steam Power Plant System...................... 86

Fig. 50 An Example of Rule Definition in Steam Power Plant System.................89 
Fig. 51 Trend Charts for Steam Pressure, Steam Flow Rate and Steam Temperature \&

Risk Carts for Steam Pressure, Steam Flow Rate and Steam Temperature....91

Fig. 52 Steam Flow Rate Trend Chart and Risk Chart..................................92

Fig. 53 Steam Pressure Trend Chart and Risk Chart......................................93

Fig. 54 Steam Temperature Trend Chart and Risk Chart.....................................94

Fig. 55 Unsafe Boiler Pressure Button in Cen Nan's KBRT system....................96

Fig. 56 Risk Value vs Sample Number Graph with Base 100........................114

Fig. 57 Risk Value vs Sample Number Graph with Base e................................114

Fig. 58 Risk Value vs Sample Number Graph with Base 100,..........................116

Fig. 59 Risk Value vs Sample Number Graph with Base e............................116 


\section{List of Abbreviations}

ALARP As Low As Reasonably Practicable

API Application Programmer's Interface

BP Back-Propagation

BPCS Basic Process Control System

CA Cumulative Average

CDF Cumulative Distribution Function

CMA Cumulative Moving Average

EMA Exponential Moving Average

ESD Emergency Shutdown

ETA Event Tree Analysis

EUC Equipment Under Control

FDD First Diserete Derivative

FDI Fault Diagnosis and Identification

GDA G2 Diagnostic Assistant

GSI Gateway Standard Interface

GUI Graphical User Interfaces

GUIDE Graphical User Interface Development Environment

ICA Independent Component Analysis

IEC International Electro-technical Commission

IFD Information Flow Diagram

ISC Intelligent Supervisory Coordinator

KBRT Knowledge-Based Real Time

LCL. Lower Control Limit

MSPC Multivariate Statistical Process Control

OSHA Oceupational Safety and Health Administration

PCA Principal Component Analysis 
PFD Probability of Failures on Demand

PLC Programmable Logic Controllers

PLS Partial Least Squares

PSM Process Safety Management

RI Risk Indicator

RRF Risk Reduction Factor

SDD Second Discrete Derivative

SF Safety Function

SIL Safety Integrity Level

SIS Safety Instrumented System

SMA Simple Moving Average

SPC Statistical Process Control

SSD Safety Shutdown

UCL. Upper Control Limit

UIL. User Interfice Library

WMA Weighted Moving Average 


\section{List of Symbols}

$\begin{array}{ll}\text { C } & \text { Consequence } \\ \text { erf }(x) & \text { Error Function } \\ \text { Fap } & \text { Unprotected Risk Frequency } \\ \text { Fp } & \text { Protected Risk Frequency } \\ \text { Ft } & \text { Tolerable Risk Frequency } \\ \text { P (F) } & \text { Probahility of Fault } \\ \text { PFDavg. } & \text { Probahility of Failure on Demand } \\ \text { S } & \text { Severity of Fault } \\ f & \text { Mean } \\ \sigma & \text { Standard Deviation } \\ \omega_{*} & \text { Under-damped Natural Frequency } \\ \omega_{j} & \text { Damped Natural Frequency } \\ \xi & \text { Damping Coefficient } \\ \tau & \text { Time Constant }\end{array}$




\section{List of Appendices}

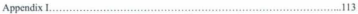

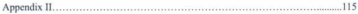

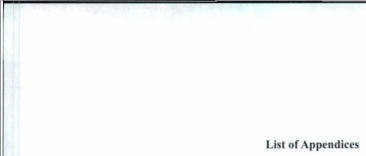




\section{Chapter 1 Introduction}

In 1987, Robert M. Solow, an economist at the Massachusetts Institute of Technology, received the Nobel Prize in economics for his work in determining the sources of economic growth. Professor Solow concluded that the bulk of an economy's growth is the result of technological advances (Crowl and Louvar, 2002). It is reasonable to conclude that the growth of an industry is also dependent on technological advances. This is especially true in the chemical industry, which is entering an era of more complex processes: higher pressure, more reactive chemicals, and exotic chemistry. More complex processes require more complex safety technology. Many industrialists even believe that the development and application of safety technology is actually a constraint on the growth of the chemical industry.

As chemical process technology becomes more complex, chemical engineers will need a more detailed and fundamental understanding of safety. Howard H. Faweett said, "To know is to survive and to ignore fundamentals is to court disaster." (Fawcett and Wood, 1982). Flixborough disaster, which happened in England in 1974, was the wake-up call for the UK. The incident resulted in 28 deaths, over 100 injuries and the complete destruction of the plant. The death toll from the Bhopal accident, which bappened in India in 1984, was over 2,000 at the time of the accident. Some recent reports place the estimates as high as 10,000 with over 200,000 injuries. Chernobyl aecident, which happened in Soviet Union in 1986, is estimably one of the worst industrial aceidents of all time. Pasadena explosion, which happened in Texas in 1989, was the wake-up call for the US with 23 fatalities and 130 injuries. Another accident in nearby Channelview killed 17 and injured over 100 less than one year later. These two accidents resulted in the Occupational Safety and Health Administration (OSHA) PSM (Process Safety Management) legislation (Gruhn, P, 1999).

As process safety incidents are still bappening today and as such ineidents sometimes 
lead to serious consequences for people, the environment and property, it is concluded that the process industry has a responsibility to further reduce occurrence of these incidents. Due to the observed changing situation in the process industry, characterized by a changing kind of incident scenarios and causes, a need exists for a changing kind of control over process safety (Knegtering and Pasman, 2009).

In an increasingly multidisciplinary engineering environment, and in the face of ever increasing system complexity, there is a growing demand for engineers and technicians involved in process engineering to be aware of the implications of designing and operating safety-selated systems. Safety Instrumented Systems play a vital role in providing the protective layer functionality in many industrial process and automation systems.

\subsection{Safety Instrumented System}

The International Electro-technical Commission (IEC) 61508 (2000) standard defines Safety Instnumented System (SIS) as "a system composed of sensors, logic solvers and final-control elements for the purpose of taking the process to a safe state, when predetermined conditions are violated". SISs are also called emergency shutdown (ESD) systems, safety shutdown (SSD) systems, and safety interlock systems.

Safety instrumented systems (SIS) are used in the oil and gas industry to detect the onset of hazardous events and/or to mitigate their consequences to humans, material assets, and the environment (Lundteigen and Rausand, 2007). A SIS generally consists of one or more input elements (e.g., sensors, transmitters), one of more logic solvers (e.g., programmable logic controllers [PLC], relay logic systems), and one or more final elements (eg., safety valves, circuit breakers), as shown in Fig. 1. 


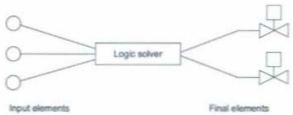

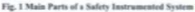

\subsection{Process Control System and SIS}

As illasirated in Fie 2, it is generally preferable that any protection sysiem (including a \$15) be kept functionally sepante from the Basic Process Control System (BPCS) in terms of its ahility to operne independent of the strate of the BPCS. The operating equipuent is albo keewu as the Equipment Under Centeol (TUC). In essenee, protection systems should be capahle of functioning to protect the EUC when the process control system is in fault. Where separation $\mathrm{b}$ not possible because the safery functions are integral with the process control syntem all parts of the system that have safety-related finctions should be rogarded af a SIS for the purposes of afety integrity assessment.

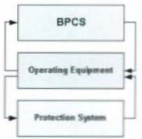

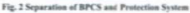


Fig, 3 shows the basic layout of a typical SIS (in this case controlling a shutdown valve as the firal control clement).

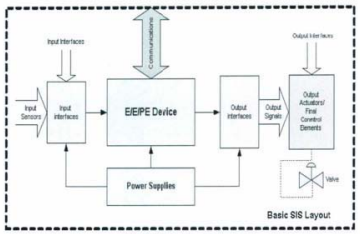

Fig. 3 itanie SIS L.wout

The basic SIS layout comprises:

- Sensor(s) for sigeat input and power

- Inpat signal interfacing and processing

- Logie solver with associated communications and power

- Oetput signal processing, interfacingand power

- Actuators and valve(s) or swiching devices to provide the final control element function.

The scope of a SIS encompasses all instumentatioa and controls that are responsible for bringing a process to a safe state in the erent of an unaceeptable deviation or failure. 


\subsubsection{Risk and Risk Reduction Methods}

Safety can be defined as "freedom from unacceptable risk". This definition is important, because it highlights the fact that all industrial processes involve risk. Absolute safety, where risk is completely eliminated, can never be achieved; risk can only be reduced to an acceptable level. Therefore all risks should be dealt with on the ALARP basis, i.c. the target is to ensure that risk is reduced to As Low As Reasonably Practicable. The ALARP principle provides a general objective of SIS, which is to reduce the frequency at which a hazard may occur to an acceptable or at least a tolerable level

Process risk is defined by the frequency of the occurrence and the potential consequence severity of the process hazard (Summers, 2007). The formula for risk is:

\section{Risk $=$ Hazard Frequency $*$ Hazard Consequence}

To define the frequeney, the initiating events are identified for each process hazard, and their frequency of oceurrence is estimated. The consequence severity is the logical conclusion to the propagation of the process hazard if no protection layers are implemented as barriers to the event.

Safety Methods employed to protect against or mitigate harm/damage to personnel, plant and the environment, and reduce risk include:

- Changing the process or engineering design

- Increasing mechanical integrity of the system

- Improving the BPCS

- Developing detailed training and operational procedures

- Inereasing the frequency of testing of critical system components

- Using a SIS 


\section{- Installing mitipating equpument}

Fif 4 illautrates the ahove meavars in terms of employing protective layers am robace risk to an acceptable level. The amount of risk rculaction for cack layer is dependent on the nuhase of the nuk and the amoust of nak rediaction affionded by the appioicatle layer cmployed frotestive layer can be furner clavsified as either Prevention or Mitigation layen. The former are put in place to shep harardous occumences and the lamer are

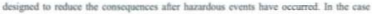
illustratod in Fie, 4, the protective layers are further wab-divided into in-plant and extemal arcan. Methods that provide laycre of protection should be independent, reliable, atiditable and devigned specifically for the nik invalved

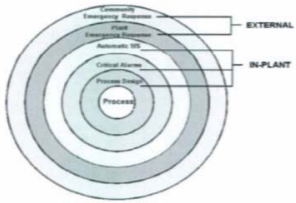

Pe 4 Saliny Frebestive Lasen

\subsubsection{Safety Fuactien (SF)}

In proves industry, a sefety function is definod ax: A set of specific actions to be taken under eqecific cincumutunes, which will move the chemical procese from a potentiafly 
unsafe state to a safe state (Marszal etc., 2003). A safety function works as a protection against a specific and identified hazardous event. It is a method to define the functional relationship between inputs and outputs in SIS. Inputs can be reganded as sensors, outputs can be regarded as final control elements and safety function can be regarded as a logic solver.

SF is able to assist SIS to reduce the risks. The amount of risk reduction can be measured based on the calculated Probability of Failures on Demand (PFD), which is the probability that SF fails to maintain safe state when predetermined safery conditions are violated. Safety function only reduces risk and will never completely eliminate the risk. However, it would be sufficient to reduce the risk to an acceptable level. 


\subsection{Safety Analysis}

\subsubsection{Risk Classification}

Unlike the convenient units like volt or kilogram, there is no universal unit for risk. Scales for one industry may not suit those in another. Fortunately, the method of calculation is generally consistent and it is possible to arrive at a reasonable scale of values for a given industry. As a result, IEC have suggested using a system of risk classification that is adaptable for most safety situations. Referring to Annex B of IEC 61508 part 5 , the risk classification table is provided as shown in Table I.

Table 1: Risk Classification of Accidents: Table B1 of IEC 61508-5

\begin{tabular}{|l|c|c|c|c|}
\hline \multirow{2}{*}{ Frequency } & \multicolumn{4}{|c|}{ Consequences } \\
\cline { 2 - 5 } & Catastrophic & Critical & Marginal & Negligible \\
\hline Frequent & I & I & I & II \\
\hline Probable & I & I & II & III \\
\hline Oecasional & I & II & III & III \\
\hline Remote & II & III & III & IV \\
\hline Improbable & III & III & IV & IV \\
\hline Incredible & IV & IV & IV & IV \\
\hline
\end{tabular}

The risk classification mentioned in Table 1 is a generalized version that works like following:

- Determine the frequency element of the EUC risk without the addition of any protective features (Fnp):

- Determine the consequence $\mathrm{C}$ without the addition of any protective features;

- Determine whether for frequency Fnp and consequence $\mathrm{C}$, a tolerable risk level is 
achieved.

If, through using Table 1, this leads to risk Class 1, then further risk reduction is required. Risk class IV or III would be tolerable risks. Risk class II would require further investigation.

In practice, this Table 1 is a generic table for adaptation by different industry sectors. It is intended that any given industry sector should insen appropriate numbers into the fields of the table and hence establish acceptable norms. For example, in Table 2, sotne trial values have been inserted.

Table 2: Risk Classification of Accidents: Trial Values

\begin{tabular}{|l|c|c|c|c|}
\hline Frequency & Catastrophic & Critical & Marginal & Negligible \\
\cline { 2 - 5 } & $>1$ death & $\begin{array}{c}\text { I death or } \\
\text { injuries }\end{array}$ & Minor injury & Prod loss \\
\hline I per year & I & I & I & II \\
\hline I per 5 years & I & I & II & III \\
\hline I per 50 years & I & II & III & III \\
\hline I per 500 years & II & III & III & IV \\
\hline 1 per 5000 years & III & III & IV & IV \\
\hline 1 per 50000 years & IV & IV & IV & IV \\
\hline
\end{tabular}

\subsubsection{Risk Reduction Terms and Equations}

The terms and equations that can be used to define the risk reduction are as follows (MacDonald, 2004):

$\mathrm{Ft}=$ Tolerable Risk Frequency 
Fup - Unprotected Risk Frequency

$F_{p}=$ Protected Risk Frequency

RRF $=$ Risk Reduction Factor

PFDavg. - Probability of Failure on Demand

$\mathrm{RRF}=\mathrm{Fnp} / \mathrm{Ft}$

PFDavg $=1 / \mathrm{RRF}=\mathrm{Ft} / \mathrm{Fnp}$

\subsubsection{Safety Integrity Level (SIL)}

SIL represents the amount of risk reduction that is required from a safery function. IEC 61508 defines SIL as "a discrete level (one of four) for specifying the safety integrity requirements of safety function." (2000). Safety integrity level 4 (SIL4) is the highest level and safety integrity level 1 (SIL.1) is the lowest one.

SIL has become increasingly part of the design and operation of safety instrumented system (Kirkwood and Tibbs, 2005). Companies are now specifying SIL based on the amount of risk reduction that is required to achieve a tolerable risk level. The SIS is designed to meet or exceed this level of performance.

How do we decide when to use a safety instrumented system and how good must it be? The answer is: it depends on the amount of risk reduction required after the other devices have been taken into aceount. The measure of the amount of risk reduction provided by a safety system is ealled the Safety Integrity, and it is illustrated by Fig. 5 from IEC. 


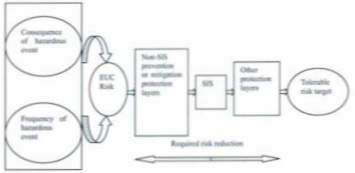

Fig 4 Hisk Hederties

This disgram defines safery integrity as upplicable ve all risk reductoon facilities. Whea it is appliod to the safery instrumented sysem, however, it becomes a measure of the system's performance.

In order to seale the performance, safery integrity levets or SILs are used. The SILs are derived from eartier concepts of gradiag or classification of safety systems. The priaciple is illustrated in Fig. 6 where the layer of protection provided by an SIS is quantifiod as a rikk ratuction factar (RRF), which eas le coaverted into a PFDavg and teferenced is an SIL tabie. 


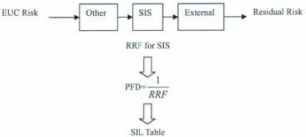

Fig. 6 Deternination of SIL.

Fesentially the SIL table provides a clas of safety integrity to meer a range of PFDavg values. Henee, the performance level of safety instrumentation meoded to meet the SIL is divided into a small number of eategories or gndes.

The IEC standard provides the follewing table for SIL.s.

Table 3: Definitions of SII s for demand mode of operation from IEC 61511-1

\begin{tabular}{|l|l|l|}
\hline SIL & Range of Averaged PFD & Range of RRF \\
\hline 4 & $10^{-1}<-$ PFD $<10^{-4}$ & $100,000>$ RRF $>10,000$ \\
\hline 3 & $10^{-4}<-$ PFD $<10^{-3}$ & $10,000>=$ RRF $>1000$ \\
\hline 2 & $10^{-3}<=$ PFD $<10^{-2}$ & $1000>-$ RRF $>100$ \\
\hline 1 & $10^{-2}<=$ PFD $<10^{-1}$ & $100>-$ RRF $>10$ \\
\hline
\end{tabular}

An SIL I system is not as reliable in providing risk reduction as SIL 2; an SIL 3 is even more reliable. Onec we have the SIL, we will know what quality, complexity and cost are going to consider. 


\subsubsection{Event Tree Analysis (ETA)}

An event tree is a graphical logie model that identifies and quantifies possible outcomes following an initiating event (Ghodrati etc, 2007). Event trees begin with an initiating event and work toward a final result. This approach is inductive. The method provides information on how a failure can occur and the probability of occurrence. When an accident occurs in a plant, various safety systems come into play to prevent the accident from propagating. These safety systems either fail or sueceed. The event tree apptoach includes the effects of an event initiation followed by the impact of the safery systems.

The typical steps in an eveat tree analysis are:

1. Identify an initiating event of interest,

2. Identify the safety functions designed to deal with the initiating event,

3. Construct the event tree, and

4. Describe the resulting accident event sequenees.

If appropriate data are available, the procedure is used to assign numerical values to the various events. This is used effectively to determine the probability of a certain sequence of events and to decide what improvements are required. An example of event tree analysis is shown in Fig. 7. 


\begin{tabular}{|l|l|c|l|l|l|}
\hline $\begin{array}{c}\text { Initiating } \\
\text { vont }\end{array}$ & Srart of fire & $\begin{array}{c}\text { Sprinilez } \\
\text { ystem does } \\
\text { not function }\end{array}$ & $\begin{array}{l}\text { Fire alam is } \\
\text { not activaled }\end{array}$ & Outcomes & $\begin{array}{l}\text { Frequency } \\
\text { (per ycar) }\end{array}$ \\
\hline
\end{tabular}

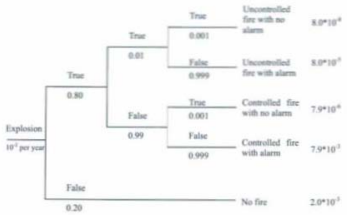

Vie T An Erample of Eivet Tree Analyeih

The initiating cucnt is unully a fallurchandesired event concsponding to a release of failure/harard In the above example, the initiating event is "Explosion", and the frequency of this incident is $10^{7}$ per year. The safkty functions are actions or barrien that can interrupt the sequence from an initiaing event to a fallare harandous outcome. In the above cuamplc, the safcry functions ate iprinkler vostem finctions and activating the flec

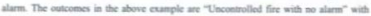

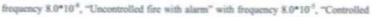

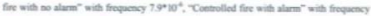

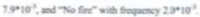




\subsection{Statistical Process Control}

\subsubsection{Introduction}

Statisties is a matheratical science pertaining to the collection, analysis, interpretation or explanation, and presentation of data (Moses etc., 1986). Statistical Process Control is defined as a system that uses statistics to identify special causes of variation in a process (Leonard, 1996). Statistical Process Control (SPC) was pioneered by Walter A. Shewhart in the early 1920s. W. Edwards Deming later applied SPC methods in the United States during World War II, thereby successfully improving quality in the manufacture of munitions and other strategically important products. Deming was also instrumental in introducing SPC methods to Japanese industry after the war had ended. In 1989, the Sottware Engineering Institute introduced the notion that SPC can be usefully applied to non-manufacturing processes, such as software enginecring processes. Through surveys and researches, I deeply believe that SPC method can be applied in the process industry, that is, to be utilized in my development for the fault diagnosis and real time monitoring of the process system.

Statistical Process Control (SPC) is an effective method of monitoring a process through the use of eontrol charts. Control charts enable the use of objective criteria for distinguishing background variation from events of significance based on statistical techniques. Much of its power lies in the ability to monitor both process center and its variation or deviation about that center. By collecting data over time at various points within the process, variations or deviations in the process can be detected and clearly displayed. If the deviation exeeeds thresholds predefined, then a fault probably occurs. In this research, SPC will be used as a fault diagnosis method to perform fault diagnosis function to the process systems. 


\subsubsection{Control Chart}

A control chart is a statistical tool used to distinguish between variation in a process resulting from common causes and variation resulting from special causes. It presents a graphic display of process stability or instability over time.

Every process has variation. Some variation may be the result of eauses which are not normally present in the process. This could be special cause variation. Some variation is simply the result of numerous, ever-present differences in the process. This is common cause variation. Control Charts differentiate between these two types of variation.

In general, control chart contains a center line that represents the mean value for the in-control process. Two other borizontal lines, called the upper control limit (UCL) and the lower control limit (LCL), are also shown in Fig. 8. These control limits are chosen so that almost all of the data points will fall within these limits as long as the process remains in-control. If a single quality characteristic has been measured or computed from a sample, the control chart shows the value of the quality characteristic versus the sample number or versus time.

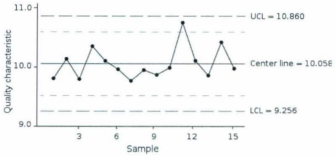

Fig. 8 An Example or Control Chart 
The purpose in adding warning limits or subdividing the control chart into zones is to provide early notification if something is amiss. Instead of immediately launching a process improvement effort to determine whether special causes are present, the quality engineer may temporarily inerease the rate at which samples are taken from the process output until it's clear that the process is truly in control.

One goal of using a Control Chart is to achieve and maintain process stability. Process stability is defined as a state in which a process has displayed a certain degree of consistency in the past and is expected to continue to do so in the future. This consistency is characterized by a stream of data falling within control limits based on plus or minus 3 standard deviations (3 sigma) of the centerline (Wheeler and Chambers, 1992).

\subsubsection{Time Series}

In statistics, signal processing and financial mathematics, a time series is a sequence of data points, mensured typically at suceessive times spaced at uniform time intervals. Examples of time series are the daily closing value of the Dow Jones index or the annual flow volume of the Nile River at Aswan. Time series analysis comprises methods for analyzing time series data in order to extract meaningful statistics and other characteristics of the data. Time series forecasting is the use of a model to forecast future events based on known past events: to predict data points before they are measured. An example of time series forecasting in econometrics is predicting the opening price of a stock based on its past performance.

An example of time series for random data plus trend, with best-fit line and different smoothing is shown in Fig. 9. 


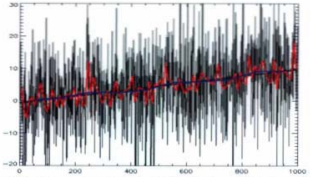

Fig. 9 Time Series: rundem dafa ples tresed, vith beti-fit line asd different smeothings (enswikipedia.ore)

Time series data have a natural temporal endering. This mukes time series analysis distinct from other common data analysis problens, is which there is no natural ondering of the abservations. Time series analysis is sles distinct from upatial data amalysis where the observations typically relate to geographical locatioos. A time series model will generally refloct the fact that observations close together in time will be more closely related than observations further apart. In addition, time series models will offen make use of the natural one-way oedering of time so that values for a given period will be expressed as deriving in some way frem past valucs.

\subsubsection{Moving Average Techniques}

Moving average technique will be utilined in my develepment. In statistics, a moving average, also called rolling average, rolling mean of runing average, is a type of finite impolse response filter used to analyze a set of datu points by ereating a series of averages of different subsets of the full data sct. A moving average is commonly used with time series data to smooth out short-tern fluctuations and highlight longer-term trends or cycles. The threshold between short-term and lony-term depends on the application, and 
the purancters of the meving averape vill be set accondingly. For ecumpic, it is aften usod in technical anabsis of financial dita, like stock prices, nenums or trating volames. It is ahe wert in economice to cramine gross domeatic prodoct, enployment or edher macroeconomic time seriex. Mathemurically, a moving avernge is atwo similar wo the low-pass flicr unct in signal procssibs.

An eample of Moving Average ef stock price chant is shown in Fis 10.

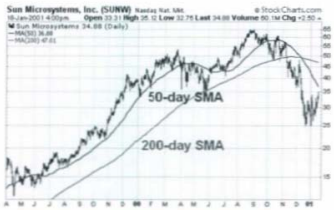

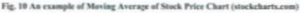

Followings are varioun typo of Moving Averape techniques:

1. Simple Maving Awerage (SMM)

A simple moving averaye (SMA) is the urweighted mean of the previous n data points For example, a 10-day simple moving avarage of elosisg price is the mean of the previous 10 days cloning prices. If those prices ant $\mathrm{Pu}_{4} \mathrm{R}$. $1, \ldots$, Pas then the formula is: 
$S U_{t}=\frac{P_{w}+P_{u-1}+\ldots+P_{w-}}{10}$

When calculating sexcessise values, a new valoe comes into the sum and an old valoc drops out, meaning a full summation each fime is annecesary.

$S M_{-1}=5 M_{2}-\frac{P_{x}=}{n}+\frac{P_{x}}{n}$

In technical analysis, there ane various popular values for a, the 10 drys, 40 drys, of 200 days. The period selected depends an the kind of movement one is concentrating on, sach as short, intermediate, or long term.

\section{Cumulative Moving Average (CMA)}

In some data acquisition systems, the data arrives in an ordered data stream and the statistician would like to get the awerage of all of the data up until the curreat data point. For example, an investor may want the average price of all of the stock transactions for a particular stock up until the current time. As each sew transaction occurs, the average price at the time of the transaction can be calculated for all of the trancactions up to that point using the cumulative average. This is the camulative average, which is typically an unweighted average of the sequence of $i$ values $x_{4}, \ldots x$ पp is the current time:

$C_{1}=\frac{x_{1}+\ldots+x_{1}}{i}$

The brute force method to calculate this would be wo store all of the data and calculate the sun and divide by the mumber of data points every time a new data point arrived. However, it is possible to simply update cumulative average as a new value $\mathrm{x}$; becomes 
avalable, using the formula:

$$
C t_{n+1}=\frac{x_{n+1}+i C A}{i+1}
$$

where CAs can be taken to be equal to 0 .

The dorivation of the cumalative arerage formula is

$$
\mathrm{CA}_{\mathrm{m}+1}=\mathrm{CA}+\frac{\mathrm{x}_{\mathrm{ti}}-\mathrm{CA}_{1}}{\mathrm{i}+1}
$$

Thas the current cumalative average sot a new dath point is equal to the previous cumulative average plas the differeace between the latest dita point and the previous average divided by the number of points received so far. When all of the data points artive $(i=\mathrm{N})$, the cumulative average will equal the final average.

\section{Weighted Moving Average (WMA)}

A weighted averuge is any average that has maltiplying factors to give different weights to different data points. Mathematically, the moving average is the coavolution of the data points with a moving average function; in technical analysis, a weighted moving average (WMA) has the specifie meaning of weights that decrease arithnctically. In an n-day WMA the latest dyy has weight n, the second lateat n - 1, ete, down to zero.

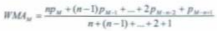


The deaominator is a triangle number, and ean be easily eomputed as $\frac{n(n+1)}{2}$.

When calculating the WMA across successive values, if we denote the sum

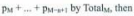

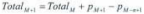

$$
\begin{aligned}
& \text { Nemerator }_{N+1}=\text { Nameralar }_{M}+n P_{N+1}-\text { Total }_{N} \\
& W M A_{s+1}=\frac{\text { Nunierator }_{M-1}}{n+(n-1)+\ldots+2+1}
\end{aligned}
$$

Fig. 11 shows how the weights decrease, from highest weight for the most recent data poinis, down to zero.

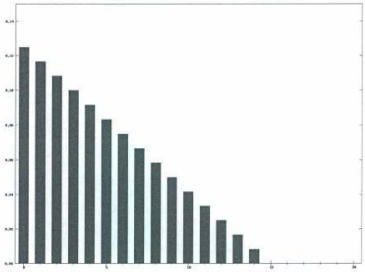

Fig. II WMA Weights (n=15) 


\section{Exponential Moving Avernge (EMA $\propto$ EWMA)}

An exponential moving average (EMA), sometimes also called an exponentially weighted moving average (EWMA), applies weighting factors which decrease exponentially. The weighting for each older data point decreases exponentially, giving much more importance to recent observations whils still not discarding older observations entirely. Fig, 12 shows an example of the weight dectease

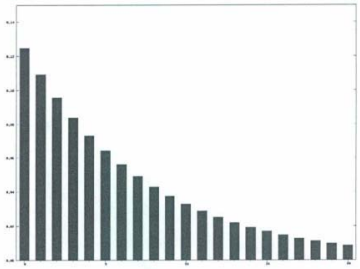

Fis 11 EMs Weights

The degree of weighing decrease is exprsssed as a constast smoothing factor 0 , a number between 0 and 1. The formula for calculating the EMA is:

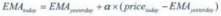


Expanding out EMA the weighting factor on each data point p1, p2, etc, decrease exponentially:

$$
E M A=\alpha \times\left(p_{1}+(1-\alpha) p_{2}+(1-\alpha)^{2} p_{3}+(1-\alpha)^{3} p_{4}+\ldots\right)
$$

This is an infinite sum with decreasing terms.

SMA technique is intuitive and simple. CMA technique is not as intuitive and simple as SMA, but it is more efficient in detecting small shifts. EWMA technique is used for detecting small shifts, like $0.5 \sigma$ to $2 \sigma$ in the process mean. 


\subsection{Objectives of this Research}

As process industrial systems become larger and more complex, the total amount of energy and material being handled increases, making fault diagnosis and safety management considerably important both from the viewpoint of process safety as well as economic loss. There exist various kinds of methods to do the fault diagnosis and safery management to the industrial processes. However, due to the limitations in various methods, the effects for fault diagnosis and safety management are not that desirable. For this reason, Venkatasubramanian etc. (2003) even proposed to develop hybrid systems to overcome the limitations of individual solution strategies.

Motivated by the desire of seeking an effective approach to perform fault diagnosis and implement safety management in process systems, and by the current situation for solving this problem in academia, an innovative methodology of risk-based SPC fault diagnosis and its integration with Sefety Instrumented. System is proposed in this thesis. To verify this methodology, G2 development software from Gensym Corporation is utilized in this research.

The overall objectives for this research are as follows

- To propose an innovative methodology of risk-based SPC fault diagnosis and its integration with SIS to solve the fault diagnosis and safety management problem in process enginecring

- Using G2 development environment, to implement and verify the proposed methodology in a tank filling system developed with $\mathrm{G} 2$ software.

- Realizing a technique breakthrough, from univariate control to multivariate control for SPC fault diagnosis, in process fault diagnosis field.

- Simulating a real process system, the steam power plant system, in G2 development environment, to testify the proposed methodology. 


\subsection{Organization of this Thesis}

Six chapters are included in this thesis. In Chapter 1, the knowledge of SIS, safety analysis and statistical process control are introduced. The objectives of this research are also presented in this chapter. In Chapter 2, the existing fault diagnosis methods are first reviewed. Then, an innovative methodology of fault diagnosis and safety management for process system is proposed and verified theoretically. At last, the G2 development environment is introduced. In Chapter 3, the proposed methodology is implemented and verified in the $G 2$ development environment through developing a tank filling system. Meanwhile, the proposed methodology is testified that it neither depends on any model, nor depends on large historical data. To demonstrate the advantages of the proposed methodology, a comparison between the tank filling system developed with the proposed methodology and a traditional design for the same system is held. In Chapter 4, the proposed methodology is further implemented and verified in the $G 2$ development environment through developing another process system, the steam power plant system. In the meantime, a technique breakthrough is made in this chapter. At the end of this chapter, a comparison between the steam power plant system developed with the proposed methodology and the traditional expert systems method for the same system is held. In Chapter 5, the ten characteristics of the proposed methodology are listed. In Chapter 6, conclusion for this proposed methodology is made, and the future works for this research are presented. 


\section{Chapter 2 Methodology of Risk-based SPC Fault Diagnosis and Safety Management for Process System}

\subsection{Review of Existing Fault Diagnosis Methods}

In the area of process fault diagnosis, the term fault is generally defined as a departure from an acceptable range of an observed variable or a calculated parameter associated with a process (Himmelblau, 1978). This defines a fault as a process abnormality or symptom, such as high temperature in a reactor or low product quality and so on. The underling cause( $(\mathrm{s})$ of this abnormality, such as a failed coolant pump or a controller, is (are) called the basic event(s) or the root cause(s). The basic event is also referred to as a malfunction or a failure. Early detection and diagnosis of process faults while the plant is still operating in a coatrollable region can belp avoid abnormal event progression and reduce productivity loss:

From a modeling perspective, there are methods that require accurate process models, semi-quantitative models, or qualitative models. On the other hand, there are methods that do not assume any form of model information and rely only on historical process data. Wc broadly classify fault diagnosis methods into three general categories. They are quantitative model-based methods, qualitative model-based methods, and process history based methods (Venkatasubramanian et al,, 2003). The elassification of fault diagnosis methods are shown in Fig. 13. 


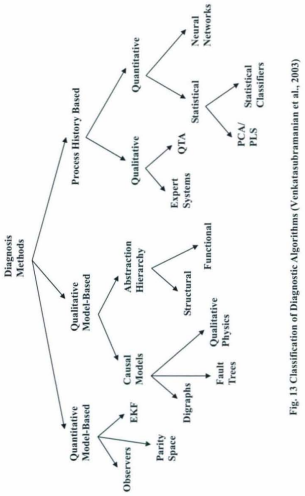


There are abundant literatures on process fault diagnosis approaches which range from analytical redundancy to knowledge-based systems and neural networks. Ghetie et al. (1998) propose a fault diagnosis approach using balance equations methods and the algorithmic redundancy. In this approach, they illustrate the algorithmic redundancy coneept using two representative fault detection and isolation methods based on balance equations. An approach of model-based fault diagnosis using knowledge base and fuzzy logic technique is presented by Mohamed et al. (2002). The input/output measurements are used to genernte analytic symptoms. Heuristic symptoms observed by the operator or based on the process history are another source for fault diagnosis, Lo et al. (2006) develop an intelligent supervisory coordinator (ISC) for process supervision and fault diagnosis in dynamic physical systems. A qualitative bond graph modeling scheme, integrating artificial-intelligence techriques with control engineering, is used to construct the knowledge base of the ISC. The model type which the analytical approaches can handle is limited to linear, and in some cases, to very specific nonlinear models. For a general nonlinear model, linear approximations can prove to be poor and hence the effectiveness of these methods might be greatly reduced. Model-based fault diagnosis requires accurate process models, while the computational complexity in real-time fault diagnostic systems and the difficulty in developing accurate process models make this approach impractical in real industrial processes. Albazzaz and Wang (2004) propose a monitoring and fault diagnosis method for process by deriving SPC charts based on ICA (Independent Component Analysis). He et al. (2006) present a novel process fault detection and diagnosis technique based on principal component analysis (PCA). The proposed method reduces the dimensionality of the original data set by the projection of the data set onto a smaller subspace defined by the principal components through PCA. A major limitation of PCA-based monitoring is that the PCA model is time invariant, while most of the real processes are time-varying. Hence the PCA model should also be recursively updated. Simani and Fantuzzi $(2000)$ propose a FDI (Fault Diagnosis and Identification) methodology. This FDI methodology consists of two stages. In the first stage, the fault is detected on the basis of residuals generated from a bank of Kalman filters; in the second stage, fault identification is obtained from pattern recognition 
techniques implemented by Neural Networks. To enbance fault diagnosis reliability, Zhang (2006) proposes a technique where multiple neural networks are developed and their diagnosis results are combined to give the overall diagnosis result. Ma et al. (2009) propose a new fault diagnosis approach with fault gradation using BP (back-propagation) neural network group consisting of 3 sub BP neural networks. According to the hazard extents and the oecurrence frequencies of different faults, the faults are divided into different grades. Neural network based fault diagnosis systems are easy to develop and can cope with nonlinearities. However, a single neural network can lack robustness, especially when the data available for training the network are not abundant.

Most of the quantitative model based approaches are based on general input-output and state-space models. One of the major advantages of the quantitative model-based fault diagnosis approach is that we can control the behavior of the residuals. However, due to system complexity, high dimensionality and process nonlinearity, it is impractical to develop an accurate mathematical model for the process system. This has limited the application of this approach in real industrial processes. Qualitative model based approaches are usually developed based on some fundamental understanding of the physics and ehemistry of the process. An important feature of this approach is that qualitative models do not require detailed process information, and the qualitative behavior can be derived even if the accurate mathematical model cannot be developed. The main disadvantage is qualitative model based method generates spurious solutions when reasoning with qualitative models. From industrial application viewpoint, the maximum number of fault diagnostic applications in process industries are based on process history based approaches. Among the process history based approaches, statistical approach seems to have been well studied and applied (Venkatasubramanian et al., 2003). Unlike model-based approaches, process history based methods do not require a priori quantitative or qualitative knowledge about the process. However, the conventional process history based methods need a large amount of historical process data. For these above reasons, Venkatasubramanian et al. even propose to develop bybrid systems to overcome the limitations of individual approach. As they said, "One realizes that no 
single method has all the desirable features one would like a diagnostic system to possess. It is our view that some of these methods can complement one another resalting in better diagnostic systems. Integrating these complementary features is one way to develop hybrid systems that could overcome the limitations of individual solution strategies."

In this situation for fault diagnosis in process engineering and the aforementioned (in Chapter 1) safety incidents happened in process industries that lead to the serious consequences for people, the environment and property, it is important and imperative for our researchers to find an effective method to perform the fault diagnosis and safety management to the process system. These factors motivated the proposal of an innovative methodology of risk-based SPC fault diagnosis and its integration with SIS for process systems in this research. 


\subsection{Proposed Methodology}

Since there are various bewildering fault diagnosis approaches in process engineering, and for the existing methods, quantitative model-based methods, qualitative model-based methods and process history based methods, each of them has its limitations, it is not an ideal solution for us to follow one branch in the classification of diagnostic algorithms shown in Fig. 13, nor the hybrid systems solution proposed by Venkatasubramanian et al.. Statistical approach is easy to build and it performs considerably well on fast detection of abnormal situations, and it has been successfully implemented in industrial applieations, but it belongs to the conventional process history based method, that means it needs a large amount of historical process data. If we cut the dependence between statistical and a large mount of historical process data which are required by the conventional process history based method in Fig. 13, and we do not use any branches below statistical method, i.e., PCA.PLS or Statistical Classifiers, then this brand new approach is desired to be an ideal solution for this process fault diagnosis problem, because it will neither depend on a large amount of historical process data, nor have the limitations from PCA/PLS or Statistical Classifiers methods. Based on these thoughts, an innovative methodology, risk-based Statistical Process Control (SPC) fault diagnosis and its integration with SIS for process system, has been proposed. The pathway of the proposed approach for fault diagnosis in the classification of diagnostic algorithms is shown in Fig. 14. 


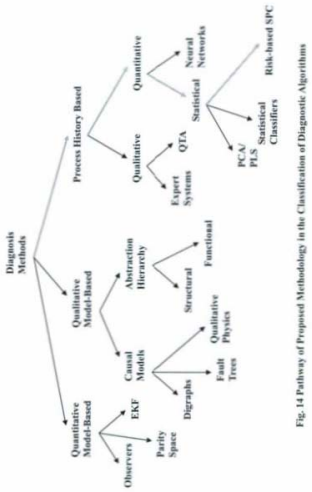




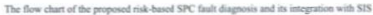
for process gqutess is shown in fife is.

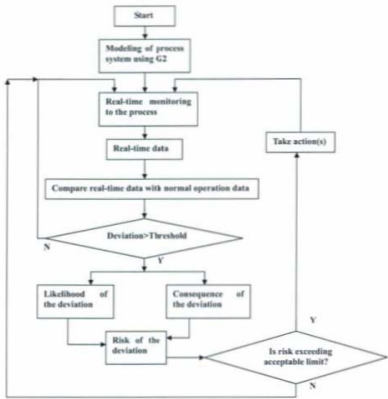

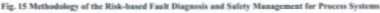




\subsection{Verification of Proposed Fault Diagnesis Methodology}

In order to theoretically verify the proposed risk-based SPC fault diagnosis methodology, historical data from Thermodynamics and Fluids Lab in Faculty of Engineering and Applied Science at Memorial University of Newfoundland will be used in this analysis. These historical data are the steam pressures of the steam power plant in the Thermodynamics and Fluids Lab. Historical data obtained during 12.49 p.m. through 12:58 p.m. on July 13,2006 are taken to do the verification. The steam pressure data in normal operation are shown in Table 4 (normal situation). A fault event is simulated in this time period, and the corresponding data are shown in Table 5 (abnormal situation).

Table 4: Steam Pressure Data for the Steam Power Plant (Normal Situation)

\begin{tabular}{|r|r|r|}
\hline Tine & $12: 49-12: 53$ & $12: 54-12: 58$ \\
\hline & 678 & 673 \\
\hline & 656 & 679 \\
\hline & 638 & 658 \\
\hline & 633 & 639 \\
\hline & 645 & 643 \\
\hline
\end{tabular}

Table 5: Steam Pressure Data for the Steam Power Plant (Abnormal Situation)

\begin{tabular}{|r|r|r|}
\hline Time & $12: 49-12: 53$ & $12: 54-12: 58$ \\
\hline & 678 & 673 \\
\hline & 656 & 700 \\
\hline & 638 & 730 \\
\hline & 633 & 639 \\
\hline & 645 & 643 \\
\hline
\end{tabular}

In this risk-based SPC fault diagnosis methodology, moving average technique will be utilized. To increase the sensitivity of the risk-based SPC fault diagnosis method to the fault event, the number of data points, 3 , is chosen to do the moving average calculation. The steam pressure data obtained for normal situation and abnormal situation are shown in Table 6 and Table 7. 

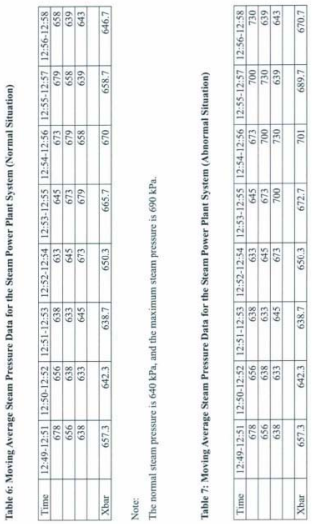


\subsubsection{Fault Diagnesis Principle}

Throesigma Rale

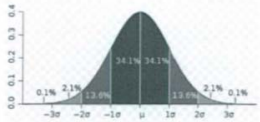

Fes 16 Sundard Doviatien Diogram

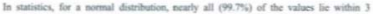

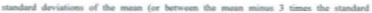
deviarion and the mean plus 3 times the sundand deviation). Satisticians ase the fellowing sotation bo reprosent this: $p=$ ie.

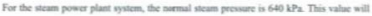
be the mean, Le, $\mathcal{K}$ in later falt diagnesis malyeik. Te maximum steam presuare is 690

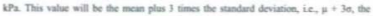
upper centrol limit (UCT) in the coetro. chart. Then the value of $\mathrm{Ja}$ is 50 , and we can obtain the meas minis 3 times the standert deviation, $16, \mu$ - 3o, the lower control limit (LCL) in the contral chart. This LCL valise is $590 \mathrm{kP}$. According to the threesigma rule. in normal situation, the data of the moving avenges of the steam pressures should fall inte the [LCL, UCL.] i.e, [590NPa, 6904Pa]. If there is a data which falls outside of this range, thes a fault could occur. In this gyitem, when the data exceeds the upper soetroi limit, $690 \mathrm{KPa}$ if could be a fault 


\subsubsection{SPC Fault Diagnosis}

1. Normality Test to the Moving Average Steam Pressure Data

In order to test if the moving average steam pressure data are normally distributed, the normality tests in Minitab 15 are conducted. The results are shown in Fig. 17 and Fig. 18.

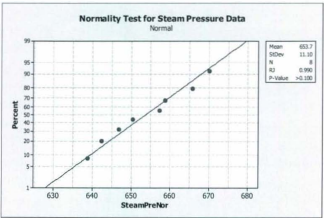

Fig. 17 Normality Test for Steam Pressure Data in Normal Situation

Fig. 17 is the normality test for the moving average steam pressure data in the Steam Power Plant System in normal operation. From Fig. 17, we can see that: The P-Value $>0$. 100 (that is, P-Value $>0.05$ ); RJ 0.990 , is very close to 1 . So the moving average steam pressure data are normally distributed. 


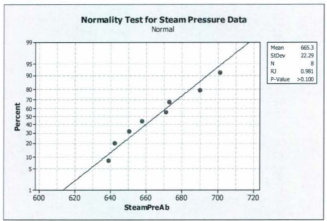

Fig. 18 Normality Test for Steam Pressure Data in Abnermal Situation

Fig. 18 is the normality test for the moving average steam pressure data in the Steam Power Plant System in abnomal situation. From Fig. 18, we can see that: The P-Value > $0.100>0.05 ; \mathrm{RJ}=0.981$, is very close to 1 . So the moving average steam pressure data are still normally distributed.

\section{SPC Fault Diagnosis Results}

If the process is in normal operation, according to the three-sigma rule, the moving average steam pressure data points should fall into the [LCL, UCL], i.e., [590kPa, $690 \mathrm{kPa}$; : otherwise, there could be a fault event. Plotting the moving average steam pressure data in Excel 2003, the following results are obtained, as shown in Fig. 19 and Fig. 20. 


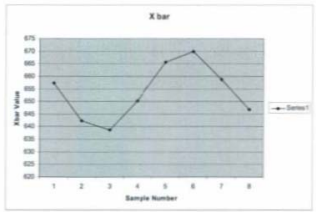

Fle 19 Line Chart for Moving Averace Siram Fresure Data in Nermal Situatima

From the above chart, we can see that the meving average itcam pressure data points fall into the $[590,690]$, so the process is in nermal sination.

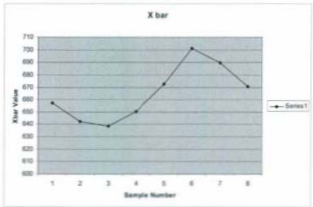

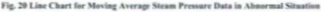


From the above chart, we can see that the sixth data point falls outside the $[590,690]$, so the process is suspected to be abnormal, i.e., there could be a fault.

\subsubsection{Risk-based SPC Fault Diagnosis}

To minimize the number of false alarms, risk or risk indicator concept is introduced into the proposed fault diagnosis methodology to identify and determine potential fautt(s) Risk is estimated for each deviation in the predicted values of control variables, using probability of the deviation and its associated severity. The probability of the fault is assessed using three-sigma rule, whereas the severity is assessed using the deviation from the predefined threshold value(s).

\section{Risk Calculation Analysis}

Aceording to the definition to the process risk, the calculation of the risk of a fault in this research is as follows,

$$
R J=R i s k=P(F) * S
$$

Where,

RI indicates Risk Indicator:

$\mathrm{P}(\mathrm{F})$ is the probability of fault. $\quad P(F)=\phi\left[\frac{x-(\mu+3 \sigma)}{\sigma}\right]$

$S$ is the severity of fault. $S=100^{\text {nn }} \quad(2-2)$

While,

$$
P(F)=\phi\left[\frac{x-(\mu+3 \sigma)}{\sigma}\right]=\int \frac{1}{\sqrt{2 \pi} \sigma} e^{\frac{\omega x}{2 \theta}} d t
$$


Where,

$$
\mu=\mu+3 \sigma
$$

From equation 2-3, we can see: in order to obtain $P(F)$, we need to do the above integral, However, in $\mathrm{G} 2$ development environment, the Integrator block passes on the Euler integral of the block's history of values.

The two types of Euler ialegrals in mathematics are:

(1). the Beta function

$$
B(x, y)=\int t^{y-1}(1-t)^{y-1} d t=\frac{\Gamma(x) \Gamma(y)}{\Gamma(x+y)}
$$

(2). the Gamma function

$$
\Gamma(z)-\int t^{x-1} e^{-1} d t
$$

Obviously, this is not suinable for the risk calculation in this research. To be able to develop this risk-based fault diagnosis nethod in $G 2$ environment, the author solved this problem through using mathemetical trassformation as follows,

From equation 2-3, as ean be seen, the Cumulative Distribution Function (CDF) is not a standard fonm; therefore, an error function, cri $O$. is introduced to standardize the $P(F)$ function

\section{Error Function:}

In mathematics, the error function (also called the Gauss ertor function) is a special 
function (non-elementary) of sigmoid shape which occurs in probability, statistics, materials science, and partial differential equations. It is defined as (en,wikipedia.org):

$$
\operatorname{erf}(x)=\frac{2}{\sqrt{\pi}} \int e^{-x^{2}} d t
$$

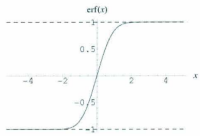

Fig. 21 Error Function

The integrand $f=\exp \left(-z^{2}\right)$ and $f=\operatorname{erf}(z)$ are shown in the complex $z$-plane in Fig. 22 and Fig. 23, 


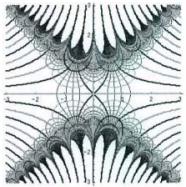

Fig. 22 Integrand $f=\exp \left(-x^{2}\right)$

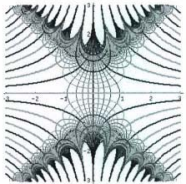

Fig, 23 erf ( $(2)$

The error function is an eatire function, it has no singularitics (cxccpt that at infinity) and its Taylor expansion always eonverges. The defining integral cannot be expluated in closed form in terms of elementary furctions, but by expanding the integrand into its Taylor series and integrating term by tern, we can obtain the erroe funcrion's Taylor series 
as:

$$
\sigma f(z)=\frac{2}{\sqrt{\pi}} \sum_{n=1}^{\infty} \frac{(-1)^{2} z^{2 n+1}}{n(2 n+1)}=\frac{2}{\sqrt{\pi}}\left(z-\frac{z^{3}}{3}+\frac{z^{3}}{10}-\frac{z^{1}}{42}+\frac{z^{9}}{216}-\cdots\right)
$$

which holds for cvery complex number . The denominator terms are sequenee A007680 in the OEIS.

In order to apply this error function in $\mathrm{G}_{2}$ development environment, we use the approximation with elementary functions to error function:

$$
e f^{2}(x)=1-\exp \left(-x^{2} \frac{4 / \pi+a x^{2}}{1+a x^{2}}\right)
$$

Where,

$$
a-\frac{8(\pi-3)}{3 \pi(\pi-4)}
$$

From above equation 2-8, we can obtuin he calculation of or $f(x)$;

$$
\begin{aligned}
& \text { When } x \geq 0, \\
& e f(x)=\sqrt{1-\exp \left(-x^{2} \frac{4\left(\pi+a x^{2}\right.}{1+a x^{2}}\right)} \\
& \text { When } x<0, \\
& \operatorname{ef}\left(x^{\prime}\right)=-\sqrt{\left.1-\exp x-x^{2} \frac{4\left(\pi+a x^{2}\right.}{1+a x^{2}}\right)}
\end{aligned}
$$

\section{Risk Calculation}


Fint, $=c$ perform the standartiration io enc abov $P(\boldsymbol{h})$

$$
z=\frac{x-p}{\sigma}
$$

Let $x=z$,

Then, we ean obain:

$$
P(F)=\alpha(r)=\frac{1}{2}\left[I+\sigma f\left(\frac{x^{\prime}}{\sqrt{2}}\right)\right]
$$

From equation 2-9, equation 2-10 and equation 2-11, we can obtain the value of $P$ (F). correspondingly, the risk value:

$$
R t=\text { Rint }=P(F) \cdot S=R(F) * 100 \text { hn }
$$

Through the above calculation, the risk valee for the peodicted values af ecntral variables will be oterined. Comespooding to the upper contral limit of the control variable, there is a risk catreme limit. Besides, we can also define ether ridk limits oe nanges for different syatems to take some specifie actions, like popping up warning mesagex, nisine an alarm er shutines dewa the system, as will be deseribed in detail in subsecuent chapter.

In the safety managernent strategy to the process sylems, two protection layers. is, Safery Invtrumented System SIS! and SW2 we the Banie Process Control Systen (BPCS). are proposed to $\mathrm{be}$ implemented inte the procenses. When any disturtance causes the monitored variable to deviate away fror the threwhold(s) for nemul operation, SIS I will detect this deviation, svaluate its risk, asd then take cortesponding action(s) to maintain the safery of the process system. In SIS1, the deviation of the controfled variahle mast have happened in the procesice. To erwure the safiety of the process system. StS2 is implemented into the wystem develogment. In S152, heliee a deviutios occirx, S152 can 
deteet this deviation in advance, and cvaluate its risk, then take corresponding action(s) promptly. After implementing the proposed strategy of SIS1 and SIS2, the Safety Integrity Level (SIL) of the safety system has upgraded from SIL1 to SIL3. 


\subsection{G.2 Develepment Environment}

Fer compica industrial processes, such as chcmical, oil, and gas proceses, conisistnthy achieving quality and cafety targets is a major challenge for process engineer. The heart

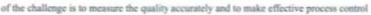
and safery mangement decisions is ral time. G2 software troe Gersy= Corporation

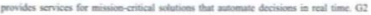

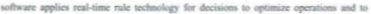
ditoct, diaganc, and roselve consly pobleme.

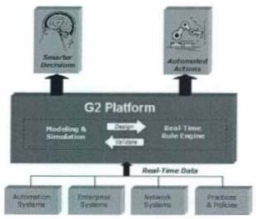

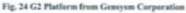

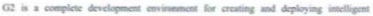

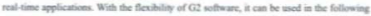
coeples situatiens: 
- Monitoring, diagnosis, and alarm handling.

- Supervisory and advanced control.

- Process design, simulation, and re-enginecring.

- Intelligent network management.

- Decision support for enterprise-wide operations.

G2 development environment is a graphical environment. Almost everything in G2 has a graphical representation. The system-defined display items in $G 2$ can show the state of the application as it changes over time, and the system-defined buttons can be used to send commands to $G 2$ or the outside world. Besides, G2 uses a structured natural language in programming statements. The G2 language is similar to ordinary human language, so the application development programmed with G2 language is easier to read.

G2 offers Gateway Standard Interfaee (GSI) network and interfacing capability. The G2 Gateway Standard Interface (GSI) is a network-oriented toolkit used for developing software interfaces, or bridges, between $G 2$ and other, external systems, G2 Gateway allows KBs to exchange various types of data between a $\mathrm{G} 2$ proeess and the bridge.

GDA, the G2 Diagnostic Assistant, is a layered product built on top of G2. GDA is a visual programming environment for developing intelligent applications that monitor and control real-time processes. A GDA application contains sebematic diagrams that

- Acquire data from real-time processes.

- Make inferences based on the data.

- Take actions based on the inference values, such as raising alarms, sending messages to operators, or concluding new setpoints.

The principal component of the GDA is a graphical language that lets you express complex diagnostic procedures as a diagram of blocks, also called an Information Flow Diagram (IFD). These blocks are connected by paths that show how data flows through 
the diagram.

GUIDE, the G2 Graphical User Interface Development Environment, is a development tool that enables users to create graphical user interfaces (GUT's) for G2 applications. A G2 GUIDE user interface can be constructed by using the graphical components ealled UIL. (User Interface Library) controls, GUIDE/UIL provides an application programmer's interface (API) to procedures that control dialogs and other elements of a graphical user interface. GUIDE supports different classes of UIL controls for different purposes:

- Some classes of UTL controls, such as edit boxes, buttons, and scroll areas, enable users to view and edit the data stored in object attributes. The different classes are suitable for viewing and editing different types of data.

- Other classes of UIL controls, such as borders and separators, enable users to organize a user interface visually.

In this research, integrated G2 development eavironment, i.e., the integration of G2\& GDA \& GUIDE, is used to develop application systems including the Tank Filling System and the Steam Power Plant System, and is also used to verify the proposed methodology of risk-based SPC fault diagnosis and safety management for process system. Recently, most fault diagnosis using G2 software employ the expert system approach. To demonstrate the advantages of the proposed methodology over expert system, a comparison will be beld between these two approaches in Chapter 4. 


\section{Chapter 3 Implementation and Verification of the Proposed Methodology in G2 Development Environment - Tank Filling System}

In order to testify the proposed methodology of risk-based SPC fault diagnosis and safety management for process system, from this chapter to next chapter, two process systems are built in $\mathrm{G} 2$ development environment. The first process system is a tank filling system, a tank level monitor, in process industry, as will be described and studied in this chapter. The second process system is a steam power plant system located in Thermodynamics and Fluids Lab in Faculty of Engineering and Applied Science building at Memorial University of Newfoundland, as will be deseribed and studied in Chapter 4.

In this chapter, the proposed methodology is implemented and verified in the G2 development environment through developing a tank filling system. Meanwhile, the proposed methodology is testified that it neither depends on any model, nor depends on large historical data. At the end of this chapter, to demonstrate the advantages of the proposed methodology, a comparison between the tank filling system developed with the proposed methodology and a traditional design for the same system is held.

\subsection{Requirements to the Tank Filling System}

In this chapter, a tank filling system, i.e., a tank level monitor, is to be developed in G2 development environment. In this system, tank is filled with inflow liquid through a manual valve. The basic process control to this filling system is to maintain the controlled variable, the tank level, at some desired value, i.e., the set point. If some disturbance causes the tank level deviate away from its set point, some protection layers, i.e., safety instrumented systems, should be added into this system to ensure system safety. The tank filling system to be developed should have the following functions: 
- Popping up warning message when tank level reaches some limit;

- Raising alarm when tank level exceeds upper control limit;

- Raising alarm when there is a fault and then shut down the system;

- Raising alarm and shut down the system immediately when there is an excessive deviation in inflow.

According to the requirements to the tank filling system to be developed, three development stages will be conducted and stadied in three subsequent sections. These three developenent stages are deterministic stage, SPC stage and risk-based SPC stage. In deterministic stage, the console for the tank filling system containing basic process control system BPCS, protection layer SIS1 and protection layer SIS2 is built in G2 development environment, and the basic funetions for this filling system are provided. In SPC stage, statistical technique of moving average is used to filter out the noise disturbances. Statistical technique of control chart is used to monitor the tank level in the whole process of the tank filling system. Besides, to ensure an event is a fault, the fault is defined as three suceessive data points of tank level exceed the upper control limit $6 \mathrm{~m}$. In risk-based SPC stage, risk indicator is introduced into the methodology to reduce the number of false alarms, real time monitoring to the process is performed, and foreeast function to the fault event is conducted. 


\subsection{Deterministic Development Sage}

\section{The Consele Constractice of the Fulling Syutem}

The purpois of a BRCS is so maintale As oontrolled variable at is set point. In this tark filling system, the convolled variable is the turk livel. The ser poins for the unk levd is set to $5 \mathrm{~m}$. Other puratecter of the tank are set $\mathrm{m}$ follows: The arta of the task is $100 \mathrm{~m} \mathrm{r}^{2}$, the muximum level is $20 \mathrm{~m}$, the upper eatrome level is $6 \mathrm{~m}$, and the lower eatreme level is $4 \mathrm{mi}$. Acoording so the roquirements, the ank filling system with BPCS is designed as Fiy 25.

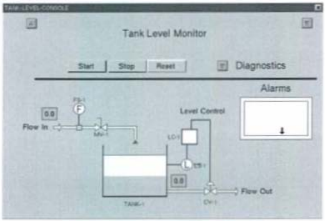

Fe. 25 Censole of the lank Levet Mtanitur with arCS

In Fie. 25, the liquid flows into tank threugh a manual valve MV-1, and the inflow rate is measurad by a flow senver FS-1. The BPCS is composed of a level senvor LS-1. a propontioeal esentroller LC-1 and a conteol valve CV.1. The purpose of BPCS is io maintain the tank levd $\mathrm{x}$ its set point $5 \mathrm{~m}$ 
If any disturtance causes the tank level deviates from its set point, it is dangerous some time in process enpincering, some protection laycr must be addod into this syotem to encure system safery. Fig 26 shows the filling system with adfing one protection layer of safety iastrumented system SISI.

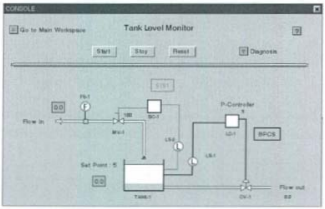

Fis. 26 Cassele of the Tank Level Meniter with aPCS \& S151

In SIS I in Fig. 26, the SISI is composed of a ievel semsor LS-2, a controller SC-I and the manual valve MV-1. If any disharbance eauses the tank level deviatos away from its set poirst $5 \mathrm{~m}$, the SISI will perform its safery function and take some actions to bring the system to a safe staie. In this development for SIS1, the sensor L.S-2 detects the curreat tank level, if the tank level exceeds set point, i.c, a fatte event happens, a warning message will pop up to wam the operatoc. If the tank level execeds the upper extreme limit $6 \mathrm{~m}$, an alarm will be raised to alert operator to shut down the system, and if the operater fails to shut down the system in specified time period, the manual valve MV-I will be shut down autamatically by the controlier $S \mathrm{C}-1$. 
In SIS1, the effects of a disturhance mus propagate through the prosess before some actions are taken, that means a falt coert must have ocewnd. From safery point of vies, it is not an ideal approach to ensure system saficy. The best strategy for process salety is to take action(s) before a fault buppens. That is the reason for adding protection layer S1S2 in this filling sysecm as shows in Fie 27.

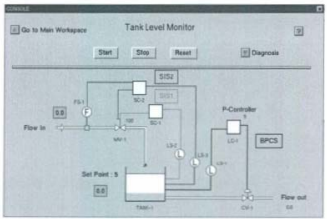

Fic 27 Caneke of the Thak Leacl Meniter wits hrCS \& SIS1 8 SIS2

In Fig 27, SIS2 is added inte the filling system to ensure the system safety, SIS2 is composed of a level senser LS-3, a controller SC-2, a flow rate sctsor and the manal valve MV-1, In SISZ, the controlled varuble is still tank level, the manipulated variable is the inflow rate, and what is concerned more herein is the inflow volume in one unit of sample time, If we calculate the coming tank level exceeds the upper limit $6 \mathrm{~m}$ through using the current inflew volume in one sample time period and the current tank level, then scme actions can be taken before the fault event happens, i.e., the tank level exceeds the upper limit $6 \mathrm{~m}$. Therefore, by using SIS2 in the development system, the fault event can be detected and identified in advance, and this has greatly improved the system kafety and reliability. 


\section{SIl Evaluation}

SIt. is defiacd as a selative lond of rak-rodustion provided by a safcty fanctive. Aeconding as the IFCSISII, the SII. of the develuped tank filling syoem is enaluated in Takle 8. fo Table 8, Stt. san be evaluated by wins coent ince analysia.

Table 8 Safery Intrgrity Level (SIL.) Ealuation to the Tank Filling System

\begin{tabular}{|c|c|c|c|}
\hline System Composition & PFDave & Risk Reduction & SIL \\
\hline BRCS & $10^{2}$ to $10^{2}$ & 10 to 100 & sil. \\
\hline BRCS-SIS! & $10^{2}=10^{-1}$ & 100 is 1000 & Sit. \\
\hline BPCS+SISI+SIS2 & $10^{-1}$ 10 $10^{7}$ & 1000 to 10,000 & SIL. \\
\hline
\end{tabular}

From Table 8, we can see: After applyine twe protection layer, SISI and STS2, the system afery integrity level has uperaded trom SIL. to SII. 3

3. The Punctions Realized in Deterniniste Stape

- Popping up warning mescage when tank level roceods set point 5 m5;

- Raising alarm when tark level escoels apper limir 6 ans

- Raising alarm when tank level is ost of control and then shut down the wyolem in specified rime period (in SIS1);

- Popping up dungerves waming mesage, raising alum and shuning dewn the vostem immediately when there is an eveesive deviation in the inflow (in SIS2). 


\subsection{SPC Development Stage}

In the deterministic development stage, only a set of deterministic results can be obtained, there are not noise filtering technique applied to the filling system to filter out noise disturbanees which could lead to false alarms, and the developed fault diagnosis function cannot perform real time monitoring to the whole process, In addition, the determination of the fault is that one data point of tank level exceeds the upper limit $6 \mathrm{~m}$, then the actions like raising alarm and shutting down the system will be taken, which will increase the probability of false alarms. Therefore, SPC fault diagnosis and safety management (SIS1 \& SIS2) method is introduced to overcome the aforementioned disadvantages in deterministic development stage.

In SPC development stage, statistical technique of moving average is used to filter out the noise disturbances. Statistical technique of control chart is used to monitor the tank level in the whole process of the tank filling system. Besides, using control chart and three-sigma rule, if three successive data points of tank level exceed the upper limit $6 \mathrm{~m}$, then this is defined as a fault event.

\section{The Developed Control Char}

The developed control chart for the tank filling system is shown in Fig. 28. 


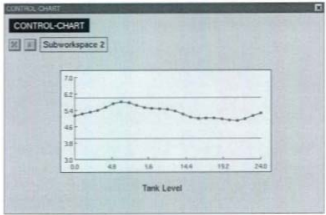

Fig. 2s Ceatrol Chart fer the Tank Falise Syten

2. The Functions Realized in SPC Stage

- Popping up waraing message when tank level exceeds set point $5 \mathrm{~m}$;

- Raising alarm with severity 1 when tank level exceeds upper limit $6 \mathrm{~m}$.

- Raising alarm with severify 2 when hree suecessive data points of tank level exeed upper limit $6 \mathrm{~m}$;

- Raising alarm with severity 3 when tank level is it range $[6.1,6.2]$, then shat dowit the system in specified time period (ia S1SI);

- Popping up dagerous warning messags, raising alarm with severity 4 and shut down the system immediately when there is an excescive deviation in the inflow (in SIS2). 


\subsection{Risk-based SPC Development Stage}

Although in SPC development stage, the developed fault diagnosis and safety management system overcomes the disadvantages existing in deterministic stage, there is not forecast capability in the SPC fault diagnosis and safety management stage. Forecast cupability is a very important characteristic for a fault diagnosis and safety management system. Using forecast capability, potential risks of the industrial processes can be identified and corrected, thus it can reduce the hazards to people, property and environment. Another drawback in SPC stage is the number of the alarms is still high. Besides, in SPC stage, real time monitoring function has not been implemented.

In order to minimize the number of alarms, perform real time monitoring to the processes and conduct forecast function to the fault event, the methodology of risk-based SPC fault diagnosis and its integration with safety instrumented system SIS1 \& SIS2 is introduced in this stage. The developed console for the tank filling system is shown in Fig. 29, Sinee this risk-based SPC fault diagnosis and its integration with safety instrumented system SIS1 \& SIS2 is the finalized proposed methodology, it will be described in detail as below. 


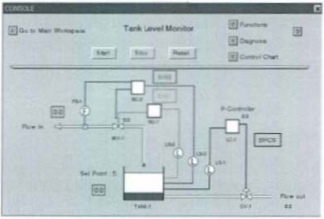

The 29 kha-trand SPC Fault Diagnesis and SISs for Tank Filling Systrm

\subsubsection{Characteristic Functions and Fault Definition}

1. The limplementation of Risk Calculation in 62 Development Emvinonment

Acconting to the risk ealculation analysis in Chapter 2 for risk-bused SPC fault diagnesis, the equations are obtained as follows:

When $x^{\prime} \geq 0$,

$\sigma(x)=\sqrt{1-\cos \left(-x^{4} \frac{4 / x+a x^{4}}{1+a x^{2}}\right)}$

When $x<0$. 
$\sigma f(x)=-\sqrt{1-\operatorname{csp}\left(-x^{2} \frac{4 / x+a x^{2}}{1+a^{2}}\right)}$

Whacte.

$$
\begin{aligned}
& a=\frac{5(\pi-3)}{3 \ln (r-4)} \\
& \mu F=\alpha(x)=\frac{1}{2} \eta+\omega f\left(\frac{x}{\sqrt{2}} H\right. \\
& R f=\operatorname{Rint}=\mathrm{A}(F) \cdot S=\mathrm{A}(F) \cdot 100^{n n}
\end{aligned}
$$

Noie:

1. Rink calculation for the tank flling wrtem is shown in the Table 11 in APPFNDX 1

2. The grapts of rick values with base 100 and with base $e$ are shown in Fig. 56 and Fig 57 in APPENDIX 1 .

To realize the calculation of the risk fir the forccasiod data points, related parametern. rules and functions are defined in the Pocedure Definition workspace, Rule workpace and Function workspace in $G 2$ developencnt enviromenent scparately, and ratinct earresponding risk ealculation through programming. Considering the transplant capability for the desclopuent, stundardvatien and modalarization designs ane utilized. A rule definition adted in the Rale wekspoce is shown in Fie. 30. 


\section{whenever stand-mov-ave receives a value and when stand-mov-ave $>0.0$ then conclude that err-func $=$ error- function $\left(0.7071^{*}\right.$ stand-mov-ave)}

Fig, 30 An Example of Rule Definition is Tank Fultiag System

\section{The Development of Forecast Function}

To perform the best linear trend forecast, the previous three data points are used to do the best fit for a line, so we can obtain the best fit value for the third point and the rate of change, i.e., the slope, of the best fit line. With this best fit line, we can predict the value of next (fourth) data point. The data points of tank level moving average and their forecasted data points are shown in Fig. 31. Since what we concem in this filling system is whether the tank level exeeeds the upper limit, only the upper control limit is drawn in the figure. 


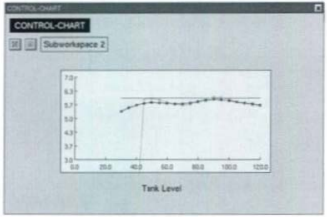

Fle 31 Data Rists in Time Order

In this chart, $\mathrm{X}$ anis is time, and $\mathrm{Y}$ mis b tank level. The rod line is the upper coemol limit. comsopending is dise tank level value $6 \mathrm{~m}$. The Black line with duta points is the ral tank level mening averge valae curve. The prem line with data points is the proticted tank level moviny averagevaloe exre.

\section{Faal: Definitice in Rink based SPC Developencns Says}

Fash is defined as three sacocssive data points exceed soms limitis). In these three data points, no waccessive dura points are the real values of the moving avernye of controlled variable, and the third naceenive data poiat is the predicted value of the moving average of controlied variable. For SISI, when two sacecesive real data points of the moving average of controlled variable exceed the upper coetrel limit, and the third suceesive predicted dats point exresds the upper control limit, conrospoding to the unacceptable risk limit 5, this cocat is defined as a fauk. For SIS2, when tow sucocisive rcal duta points of controlled variakle are above the nein value, and the third predicted data poine 
excects the upper consol limit, corroponfing to the unacecptable risk limit 5, this event is defined as a fault. For eumple, in \$ISI of the tank filting syaem, when lwo succeasive real data points of tank level moving average caceed the opper centrol limit $6 \mathrm{~m}$, and the third successive predicted data point exceods the upper control limit $6 \mathrm{~m}$, this event is defined as a fontt, as shows in Fir. 32.

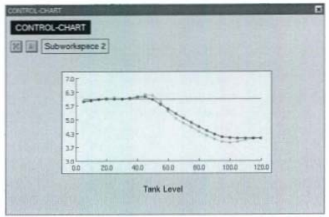

Fig. 32 Risk-based Tank Levd Contret Chart

In the charts in Fig. 31 and Fig. 32, the data points are in time erier, but the time is not real time. To perform the real time monitoring to the pencesses, trend chart is introduced into the development to the tank filling system to display the results for SISI and SISZ.

\subsubsection{The Development of SIS1}

\section{Fault Diagnosis for S15:}

In SISI, to detect fantr and take comesponding actions, the tank level dara are measured by LS.2. Affer filterod out noise by wing moving average technique with sample size 3. 
these ank level dara become tank level moving weraes data. Then through perfimming liscar trend forecast with sample sire 3 and time beriace 5 meconds the prodicied ank level valaes can be obtained from these reat dra of tank level moving avernge. Later, through doing risk calculation to the protictod tank level data, we can obtain the values of riv indicator, and then take corroponding stives like mising alarm or shuming down vosem aceoeding to the risk values.

\section{The Rewals of Ac Fault Diagnosis for SISI}

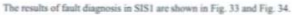

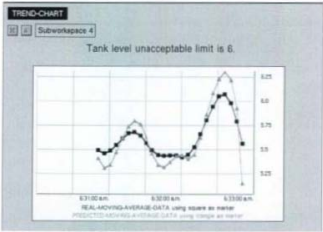

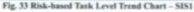

In Fig 33, $\mathrm{X}$ nis is the neal time, and $\mathrm{Y}$ axis is tank level. The hack carne is the rod tank

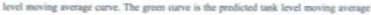
cave. We can see from this chart when inoe wocessive data points of tank level exceod

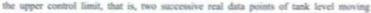


average exeed the upper control limit 6in, and one prudicted tank level for the third drta poist exceods the upper control limit, curtoponding so the unacceptabls rivk limit 5 , the system will be shut down.

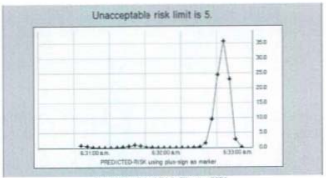

Fig. 34 Predicted Bhk Clart-SIS1

In Fig. 34, $\mathrm{X}$ axis is the real time, and $\mathrm{Y}$ axis is the risk value. The black earye is the predictod risk curve for the predicted tark level. From this chart, we ean see: when there is a fiult, there will be a very shap top in the curve.

3. The Realized Funetions in SIS1

The realized functions in S1S1 ate as follows:

- Popping up warning message when risk value for the prodicted tank level is in range 1.5:

- Raising alarm with seterity 2 when nisk value exconds 5, i.e., the pnodicted lank level cuccods upper control limit 6 ms;

- Raising alarm with severity 3 when the real tark level exceods upper control fimat 6 m; 
- Raising alarm with severify 4 when a fault happens, shutting down the system and highlighting the valve MV-1 in green.

\subsubsection{The Development of SIS2}

\section{Fault Diagnosis for SIS2}

In SIS2, to detect fault and take corresponding actions, the inflow rate is measured by FS-1. After filtered out noise by using moving avenge technique with sample size 3 , these inflow rate data become inflow rate moving average data. Then through performing linear trend forecast with sample size 3 and time horizon 5 seconds, the predicted tank level values can be obtained from these real data of tank level moving average. Using the predicted tank level, the current outflow rate and the current tank level, we can obtain the predicted tank level. Later, through doing risk caleulation to the predicted tank level data, we can obtain the values of risk indieator, and then take eorresponding actions like raising alarm or shutting down system according to the risk values.

2. The Results of the Fault Diagnosis for SIS2

The results of faulr diagnosis in SIS2 are shown in Fig. 35 and Fig. 36. 


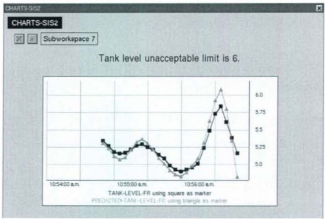

Fig. 35 Risk-based Tank Level Tread Chart - SIS2

In Fig. 35, $\mathrm{X}$ axis is the real time, and $\mathrm{Y}$ ax is is tank level. The black curve is the real tank level curve, and the green eurve is the predicted tank level curve (Note: The predicted tank level point is aligned with real tank level point by time, i.e., at the same time, the black point is the current level, and the green point is the predieted level). From this figure, we can see: when two successive real tank level data points are above mean value $5 \mathrm{~m}$, and the third predicted data point exceeds the upper control limit $6 \mathrm{~m}$, corresponding to the unacceptable risk limit 5, the system will be shut down. 


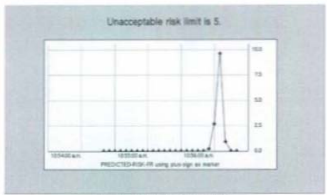

Fis. 35 Prodicind Btish Chart - Sis?

In Fig. 36, $\mathrm{X}$ asis is the toal time, and $\mathrm{Y}$ axis is the risk valac. The black curve is the prodicted rikk cane for the prodicted tark level. Form this chart, we can see whom there is a fault, there will be a very sharp top is the curve.

\section{The Realired Functions in StS2}

The realiaed functions in STSZ are as follows:

- Raining alarm with scverity 4 when there is ah cocosive deviation in inflow, shuiting down the syotem and highlighting the valve MV-1 in red.

\subsubsection{Discussien}

In StS2, the ideal situation is when twe saccesive real data points of tank level are aheve the mein valoe $5 \mathrm{~m}$ and belor the upper control fimit $6 \mathrm{~m}$, and the thind predicsod dus

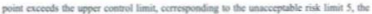


system will be shat dren. Howerer, thers caints another scenario for this situation, that is, when the provious two mecensive real tank level points ane above mean value 5 and below soper cootrul limir 6 , and the third prodicted bank lovel is below the secued data point and of coune also kelow the upper control limit $6 \mathrm{~m}$, then the neat rail tank level Anta point will occur, this real point value has the possibiliny of exceoding the uppor control limit $6 \mathrm{~m}$, as shown in Fic, 37. However, the likelihood of this sihation is very low and the rikk for this simaticen is accoptoble.

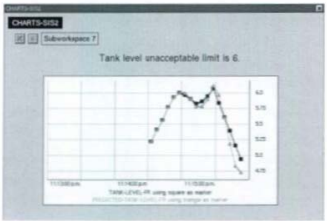

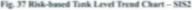

\subsubsection{Cemparison with Cen Nan's Werk}

To demonstrate the advantages of the proposed methodology of risk-based SPC fauth diagnesis and its integration with SISx, a comparioes betwees the author's work and the previous developer Ces Nas's work (Nan ef al, 2005) for the same tank filling system is held as follows 


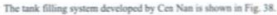

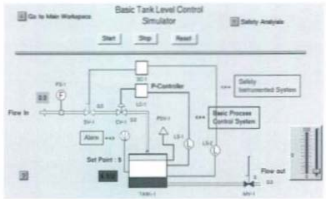

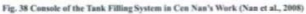

In this design shown it Fig. 38, there is one BFCS and oee SIS. The BPCS is composed of a krel scases LS-1, a proportienal watroller LC. I and a control valve CV-1, and it maintains the tank level at set point 5 m. The Sis is composed of a level sensor 1.5 .2 , a controller SC-1 and a manual valve SV-1. When the tank level evereds the upper extreme value $6 \mathrm{~m}$, which will nise an alam to the epcrator, if the operator fails to clove the SV.1 in some period, the SIS will dlone the SV-1 automatically. The fualt diagasis function develeped by $\mathrm{Cen}$ Nan afs: when turk lovel exeechs upper extreme value $6 \mathrm{~m}$, an alurm with screrity I will be raiked. When tank level is out of control, an alurm with scverity 5 will be raised and system will be shut down.

In the tank filling sysem developod by Cen Nan, there are ane BPCS and one protection Lyer SISI, and the SII. for the developed vatem is SIt.2. Whill in auther's wook for same system, there are one HPCS and hro protection layers, i.e, SISI and SIS?. The SIL. of the syoten drocloped by the author has reached SII.3. 
Real time monitoring and forecast functions are essential to the fault diagnosis in process systems. In these two developed systems, both have real time monitoring function. However, there is not any chart in Cen Nan's system for visual display, and there is not forecast function in Cen Nan's system either. While in the author's system, we can perform the best linear trend forecast to the controlled variable, the tank level, and trend chart is used to display the real data points and the predicted data points in real time.

The fault diagnosis in Cen Nan's system is in deterministic mode, and there are not SPC fault diagnosis development and risk-based SPC development, so the number of false alarms is very high. In author's system, SPC control chart techaique is used to distinguish abnormal situation from normal situation, and risk indicator is introduced into the fault diagnosis to minimize the number of false alarms.

The comparison between author's work for the tank filling system and Cen Nan's work is shown in Table 9.

Table 9: Comparisen to Cen Nan's Work for the Tank Filling System

\begin{tabular}{|l|c|c|}
\hline \multicolumn{1}{|c|}{ Characteristics } & Cen Nan's System & Huizhi Bao's System \\
\hline BICS & Yes & Yes \\
\hline SIS1 & Yes & Yes \\
\hline SIS2 & No & Yes \\
\hline Real Time Monitoring & Yes & Yes \\
\hline Trend Chart & No & Yes \\
\hline Forecast Capability & No & Yes \\
\hline Deterministic Develoginent & Yes & Yes \\
\hline SPC Development & No & Yes \\
\hline Risk-based Development & No & Yes \\
\hline Noise Filtering & Yes & Yes \\
\hline $\begin{array}{l}\text { Additional Handware for } \\
\text { Noise Filiering }\end{array}$ & Yes & No \\
\hline Sil. & & 3 \\
\hline
\end{tabular}




\title{
Chapter 4 Implementation and Verification of the Proposed Methodology in G2 Development Environment \\ - Steam Power Plant System
}

\begin{abstract}
The conventional SPC control chart method, which belongs to process history based method because a large amount of historical data are needed, was introduced into the process fault diagnosis in 1931 as the Shewhart control chart, and followed by others such as the cumulative sums chart in 1954. As the demand for product quality and process reliability is growing, the conventional SPC charts have been extensively used in industrial processes. Although the conventional SPC method is still valid now, it has vital limitation that the conventional SPC chart is a univariate control chart, and it can not handle multivariate processes and the correlation among controlled variables, thus MSPC techniques are extensively studied and used in industrial processes. Another vital limitation for the conventional SPC method is in the data acquisition technology. These two reasons are why the SPC method is not written into any branch in Fig. 13.
\end{abstract}

In this chapter, the proposed innovative methodology of risk-based SPC fault diagnosis and its integration with SIS is further implemented and verified in the $G 2$ development environment through developing another process system, the steam power plant system. In the meantime, a technique breakthrough, from univariate monitoring to multivariate monitoring for SPC fault diagnosis, is made in this chapter. To demonstrate the advantages of the proposed methodology over other traditional methods, at the end of this chapter, a comparison between the steam power plant system developed with the proposed methodology and the traditional expert systems method for the same system is held. 


\subsection{Requircments to the Steam Power Plant System}

The steam power plant is locaned in Thermodynamics and Flaids Lab in Faculty of Encineering and Applied Science building it Mernerial Chiversity of Newfoundland, as shown in Fig. 39 .

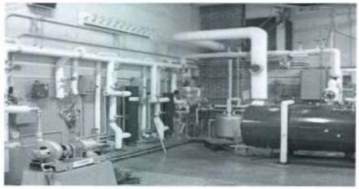

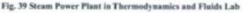

The sehematic diagram of this steam power plant is shown is Fig 40 . This steam power plant is conposed of a boiler, two superteaters, a turtsine, a coedenser, a cendensate tank. a pamp and other eomponents like preisure senson, temperatare sensors cte. Steam is generated in the boiler, after flowing throght two superheater, if reaches and drives the tuthise to produce electricity. This electricity will power ten electric bulbs. Flowing out tarbinc, the stcam is condensed inte water by coodenser, and then flows inte condemate tank so propue se be pump inte boiler toyether wib the cily water for later ase. 


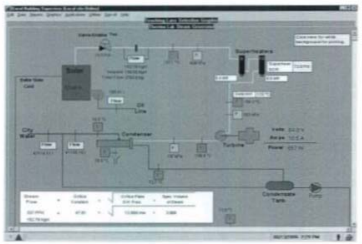

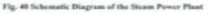

The develupment vorbs for this iteim power plant wytem inclade:

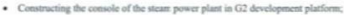

- Modeling and simalating the emtase process for the sear pouer plant in G2 enviruamcent:

- Desighing BNCS, SISI and SISZ to the coetrolled varuibles, in this devielopment spotem, the controllod variahles are free parancters of the boilex, that is, the steam flow rate, the steam presure and steam lemperatare;

- Realining a technique brcaichurough, from univariate control to multivariate control for SPC fault dagnosis, in process taltr diagnocis field.

- Applying the proposed methodalory of risktasod SPC finult diagrosis and its integration with sis imte the developed naram power plant system. 
The set points and maximums of the three parameters of the boiler are as follows: the set point and the maximum of the steam flow rate are $160 \mathrm{Kg} / \mathrm{H}$ and $166 \mathrm{Kg} / \mathrm{H}$ separately. For the steam pressure, they are $640 \mathrm{kPa}$ and $690 \mathrm{kPa}$ separately. For the steam temperanure, they are $219^{\circ} \mathrm{C}$ and $239^{\circ} \mathrm{C}$ separately. When a fault event happens in any individual controlled variable, safety system SISI should pop up a warning message. When any risk of the three controlled variable is greater than 20, the SIS1 should raise an alarm of shutting down the system with severity 4 . When the overall risk for the three parameters is in range 5-10, safety system SIS2 should pop up a warning message. When the overall risk is in range 10-20, the SIS2 should pop up a severe warning message. When the overall risk is greater than 20 , the SIS2 should raise an alarm of shutting down the system with severity 4 . 


\subsection{Console Construction in G2 Environment}

According to the description to the steam power plant system, the developed console for this system is shown in Fig. 41 on next page.

In this console, there are mainly seven subworkspaces. They are Procedure, Function, Rule, Diagnosis, Charts, Assumption and GDA Interface subworkspaces. The Procedure workspace contains all the procedure, method and parameter definitions used in this development. All the functions used in this system are defined in the Function workspace, and all the rules are defined in the Rule workspace. The functions of fault diagnosis and safery management SIS1 \& SIS2 are implemented in the Diagnosis workspace. The Charts workspace provides the real time trend charts and risk charts for the three controlled variables of the boiler in the steam power plant system. In the Assumption workspace, some assumptions about this system are listed, and in the GDA Interface workspace, some source signals are provided. In the steam power plant system, the three controlled variables are the steam flow rate, the steam pressure and steam temperature of the boiler. The BPCS for the steam flow rate consists of a flow sensor SG-FS-1, a controller SG-PC-1 and a control valve SG-CV-1. The BPCS for the steam pressure consists of a pressure sensor SG-PS-1, a controller SG-PC-2 and a control valve SG-CV-2 The BPCS for the steam temperature consists of a temperature sensor SG-TS-1, a controller SG-PC-3 and a control valve SG-CV-3, 


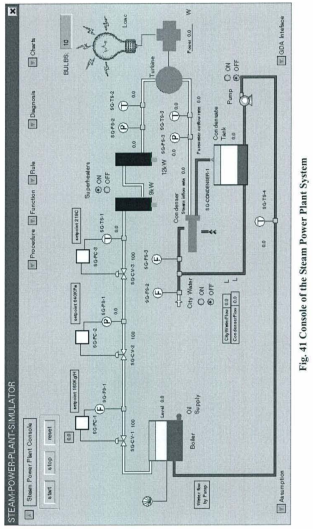




\subsection{System Modeling}

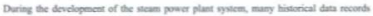

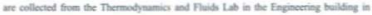

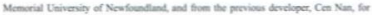
thes vystern.

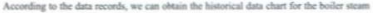

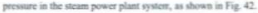

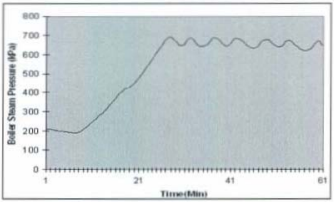

Fie 42 Histarical Data Chart fer the Beller Pram Prasure

As we can see in Fiz 42, from 200 aP2, the beiler steam prossure starts to rise and raches the stcaly sute (oscillution sate) at about $700 \mathrm{kP}$. Conpuring this procedure with the characteristic of a socond-ander sydem of under danped moponse shown in Fig. 4). 


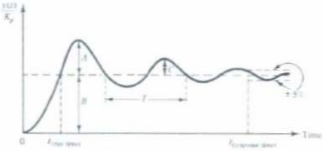

Fis 43 Characteristics of an teder-danaped Respense

We can see that the historical data chart of the boiler steam pressure is very similar to the latier system, so we can model the boile steant pressure with the second-order system of the under-damped response, that is

$$
f(n)=1-\frac{e^{-\operatorname{tw}}}{\sqrt{1-\xi^{2}}} \sin \left(n \mu+\tan ^{-1} \frac{\sqrt{1-\xi^{2}}}{\xi}\right)
$$

Whate

$$
\begin{aligned}
& \omega_{*}=\text { under-dumped natural treqpers } \\
& \omega_{2}=\text { damped nahural froquency } \\
& \xi=\text { damping coefficieat }
\end{aligned}
$$

Throuph analyzing the historical stcam fow rate data, stcam icmperature data, seam prossure data and Control \& Electrical data, and together with analyzing the physical peocess of the stcam power piast vystem, cther parameters of compcencnto can be modkled with the response of the first-onder system, that ix:

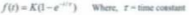




\subsection{The Implementation of the Proposed Methodology}

The proposed methodology of risk-based SPC fault diagnosis and its integration with SIS is implemented in G2 development environment in two stages, that is, SPC stage and risk-based SPC stage. These two development stages will be conducted and studied in two subsequent sections. In SPC development stage, control chart is used to distinguish abnormal situation from normal variation of eontrolled variable based on three-sigma rule and linear trend forecast. To minimize the number of false alums, in risk-based SPC development stage, risk indicators are used to identify and determine potential fault(s).

In the steam power plant system shown in Fig. 41, the controlled variables are three parameters of the boiler, that is, the steam flow rate, the steam pressure and steam temperature. In normal situation, the corresponding BPCS maintains individual controlled variable at its set point. When there is a fault or the risk value exceeds some limits, safety instrumented systems should provide warning messages or raise alarms of shutting down the system.

\subsubsection{SPC Development Stage}

In SPC development stage, control chart of the individual controlled variabie is developed To illustrate this development stage, one of the controlled variables, the boiler steam pressure, is chosen to conduct the procedure. In this stage, all the functions that Cen Nan's system has have been completed. To demonstrate the effectiveness of this SPC fault diagnosis system, an experiment is held in this stage.

\section{Fault Diagnosis in SPC Stage}

In the fault diagnosis module, the main task is to construct and develop the control charts for the process variables. Control chart is used to distinguish abnormal situation from normal variation of controlled variable based on three-sigma rule. 
The developed control chart for the steam pressure of the boilet in the steam power plant system is shown in Fig. 44.

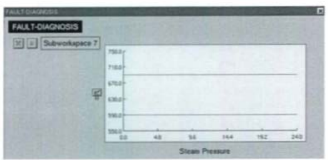

Fe, 4 Centrul Cart of the Siran Freaure is Stean Power Flant System

Fie 44 indicates wo control limits, the spper control limit $690 \mathrm{kPa}$ and the lower cantrof limit $590 \mathrm{kPa}$ for the steam prosure using two red lines. In nommal situation, real time data of the steam presure moving averige should fall ints the [ $590 \mathrm{kPa}, 690 \mathrm{kPa}]$, the range between two rod lines as shown ia Fie 45. If there is a real time duta which falls outside of this nnge as shewn in Fie 45 , then a frult could occur. In this system, when the real time data exeecd the upper contrel limit $690 \mathrm{LP}$, there coald be a fialt. 


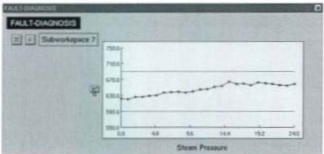

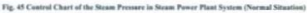

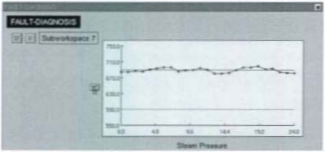

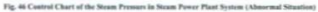

To ensure be aforementioned event is a faclt, the number of suecessive values that ciced the upper cuntrel limit is set to 3 . That means an alarm will be raised if therr are more than 3 times (inclusive) that the suceesive monitored value excoeds the upper eontrol limit. Besides, to detect and prediet the fault coent, another condition for raising securring alarm is set. The conditioe is if there are more than 3 times (ancluspe) that the monitared value eccecds the upper contud limit in a hoor: 


\section{As Experiment for Effoctiveness Dementrative}

To demonstrate the effectivemess of the developed SPC fonlt diagnosis system with traditional fault diaprosis systcms, the dovelopod STC frult diapsosis module was pot inte the same steam pourt plaet grten developed by Cen Nan whose fault diagnous macthod is knowledge-bascl real time aproach, which belongs to the Expen Systems branch in Fic. 13 and is abbesiated te K.IBRT approach in later descripticn, as shown in Fie 47

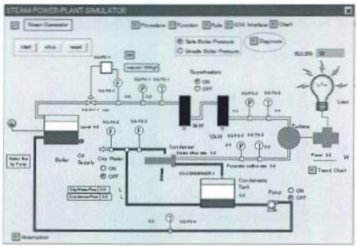

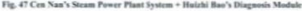

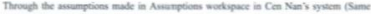
suanciuns are made in aurbor's developnem, as show in Fiz, 4 , the SpC 


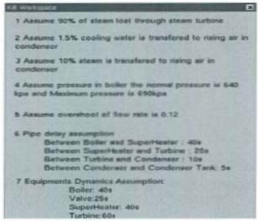

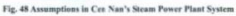

fault dagenonis modale detectod the followine problems that evist in Cen Nan's system with KRRT falt diagnowis modale:

(1). Raising false alarms when the steam prosuare data are still safe. 


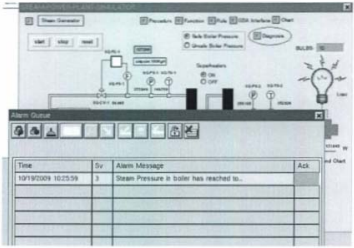

Fig. 49 Fabe Alarm is Cea Xas'stcam Pewer Plant Syatem

From 310 kPa for the steam pressure when in beating period, the sysem keeps raising alarms with the Alarm Messase Steam Pressure in boiler has reached to an unsafe paint, Pls be careful

(2). Raising false alarms when the steam pressure is still in safe range, i.e. [590 k.Pa, 690 kPa].

At $645 \mathrm{kPa}$ and $669 \mathrm{kPa}$, the system raised alarms with the Alarm Message Sieam Pressure in boiler has reached to al critical point, Pls be report to an engineer.

From the point of the ib file eapacity, the $\mathrm{kb}$ file developed by Cen Nan using KBRT fault diagnosis approach is $957 \mathrm{~KB}$, while the $\mathrm{kb}$ file using SPC fault diagnosis approach is $431 \mathrm{~KB}$ 
From this experiment, we can see the SPC fault diagnosis is more effective and accurate in fault diagnosis in process system. Using control chart, the controlled variable is monitored and displayed clearly. This feature makes the SPC fault diagnosis approach more intuitive. In addition, the SPC fault diagnosis approach is more compact than the traditional knowledge-based real time (KBRT) approach, i.e., the traditional expert systems approach.

\subsubsection{Risk-based SPC Development Stage}

In SPC development stage, there is not foreeast capability in the steam power plant system, the number of the alarms is still high, and the function of real time monitoring has not been implemented. In order to minimize the number of alarms, perform real time monitoring to the processes and conduct forecast function to the fault event, the methodology of risk-based SPC fault diagnosis and its integration with safety instrumented system SIS1 \& SIS2 is introduced in this stage. A technique breakthrough, from univariate monitoring to maltivariate monitoring for SPC fault diagnosis, is made in this stage, and so is the correlation problem among multiple variables. The developed console for the steam power plant system is shown in Fig. 38. Since this risk-based SPC fault diagnosis and its integration with safety instrumented system SIS1 \& SIS2 is the finalized proposed methodology, it will be described in detail as below.

\subsubsection{Characteristic Functions and Fault Definition}

\section{The Implementation of Risk Calculation in G2 Development Environment}

According to the risk calculation analysis in Chapter 2 for risk-based SPC fault diagnosis, the equations are obtained as follows:

When $x \geq 0$, 
$\omega f(x)=\sqrt{1-\exp \left(-x^{2} \frac{4 / x+a^{2}}{1+a x^{2}}\right)}$

When $x^{2}<0$,

$\omega f(x)=-\sqrt{1-\cos \left(-x^{2} \frac{4 / \pi+a x^{4}}{1+a x^{4}}\right)}$

Where.

$$
\begin{aligned}
& a=-\frac{B(r-3)}{3 \operatorname{rr}(\pi-4)} \\
& P(F)=\phi(x)=\frac{1}{2}\left[1+\operatorname{cof}\left(\frac{x}{\sqrt{2}}\right)\right] \\
& R I=\operatorname{Risk}=P(F) \cdot S=P(F) \cdot 100^{\text {Nin }}
\end{aligned}
$$

Note:

1. Risk calculation for the stean power plant system is shown in the Table 12 in APPENDEX II.

2. The graphs of risk values with base 100 and with base $e$ are shown in Fig 38 and Fie. 59 in APPENDIX II.

To realise the calculation of the risk for the forccasted data points, related parameters, rules and functions are defined in the Procedure Definitioe workspoce, Rule workspace and Fusetion workspace in G2 development environment separately, and realized corrciponding risk calculation throuph programming. Considering the transplant capability for the development, standardiration and modulariration designs are anitiant: A rule definition added in the Rule workspace is shown is Fie. $\mathbf{S 0}$. 


\section{whenever stand-pred-val-f receives a value and when stand-pred-val- $f>0.0$ then conclude that pred-err-func- $\mathrm{f}=$ error- function-f $\left(0.7071^{*}\right.$ stand-pred-val- $\left.f\right)$}

Fig, 50 An Example of Rule Definition is Steam Power Plant System

\section{The Development of Forecast Function}

To perform the best linear trend forecast, the previous three data points are used to do the best fit for a line, so we ean obtain the best fit value for the third point and the rate of change, i.e., the slope, of the best fit line. With this best fit line, we can predict the value of next (fourth) data point.

\section{Fault Definition in Risk-based SPC Development Stage}

Fault is defined as three successive data points exceed some limit(s). In these three data points, two successive data points are the real values of the moving average of controlled variable, and the third successive data point is the predicted value of the moving average of controlled variable. In SIS1, when two successive real data points of the moving average of controlled variable exceed the upper control limit, and the third successive predicted data point exceeds the upper control limit, corresponding to the unaceeptable risk limit 5 , this event is defined as a fault.

In SPC stage, the monitoring to the controlled variable is not in teal time. To perform real time monitoring to the processes, trend chart is introduced into the development to the steam power plant system to display the results for SISI and SISZ. 


\title{
4.4.2.2 The Development of SIS1 \& SIS2
}

\author{
1. Fault Diagnosis for SISI \& SIS2
}

In this stage, there are three controlled variables in the steam power plant system, they are the steam flow rate, the steam pressure and steam temperature of the boiler. The fault diagnosis procedure for every controlled variable is same with the description for the controlled variable of tank level in SISI of the risk-based SPC stage in the tank filling system. When two suceessive real data points of the moving average of controlled variable exeeed the upper control limit, and the third successive predicted data point exceeds the upper control limit, corresponding to the unacceptable risk limit 5 , this event is defined as a fault. When a fuult happens in any individual controlled variable, safety system SIS1 pops up a warning message. When any risk of the three controlled variable is greater than 20, the SIS1 raises an alarm of shutting down the system with severity 4 . When the overall risk for the three controlled variables is in range 5-10, safety system S1S2 pops up a warning message; when the overall risk is in range 10-20, the SIS2 pops up a severe warning message; when the overall risk is greater than 20 , the S1S2 raises an alurm of shutting down the system with severity 4 . In this process, as can be seen, the correlations among the three controlled variables are the summation of risks of three controlled variables is in range $5-10,10-20$ or greater than 20 .

\section{The Results of the Fault Diagnosis}

The results of the fault diagnosis for the steam flow rate, the steam pressure and the steam uemperature of the boiler are shown in the Fig. 51 .

In Fig 51, we can see that the three controlled variables, i.e, the steam flow rate, the steam pressure and the steam temperature of the boiler, are being monitored and analyzed simultaneously, so this process is a multivariate monitoring. 


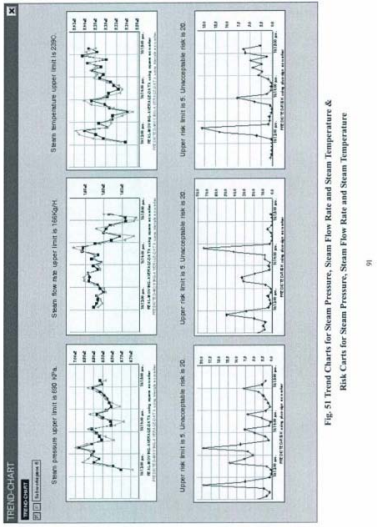


Some fautt inaphots are sboas in Fig 82 , Fie 53 md Fie 54

\section{Note:}

1. In all the following figures, the poedicted point is aligned with real point by time; ie, $x$ the same time, the blak point is the currems value, and the goven point is the predicted value

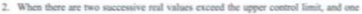

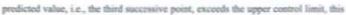
sinurive is defined as a fanth

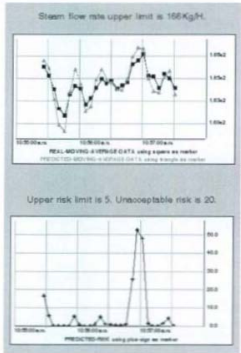

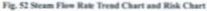




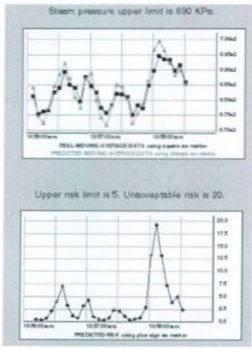

Die 53 Stram Drusars Twed Chart and Ris Chart 


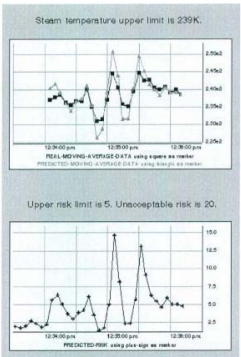

He. S4 Steam Temperature Trend Caart and Risk Chart

3. The Realized Functions in SISI \& SIS2

The realized functions in SIS ! are as follows:

- When there is a fatil in any indisidual variable, the system pops up a waming message 
- When any of the risk (risk of steam pressure, risk of steam flow rate, or risk of steam temperature) is greater than 20 , the system raises the alarm of shutting down the system with severity of 4 .

The realized functions in SIS2 are as follows:

- When the overall risk (risk of steam pressure + risk of steam flow rate + risk of steam temperature) is in range 5-10, the system pops up warning message.

- When the overall risk is in range 10-20, the system pops up severe warning message.

- When the overall risk is greater than 20 , the system raises the alarm of shutting down the system with severity of 4 .

In order to indieate the values of individual variable and its predieted value when they feach the extreme value, the following alarms are added:

- When the predieted value for any variable reaches the extreme value, the system raises an alarm with severity of 2.

- When the real value for any variable reaches the extreme value, the system raises an alarm with severity of 3 .

\subsubsection{Comparison with Traditional Approach}

To demonstrate the advantages of the proposed methodology over other traditional fault diagnosis and safety management approaches, a comparison between the proposed risk-based SPC method and the knowledge-based real time (KBRT) approach developed by $\mathrm{Cen} \mathrm{Nan}$ for the same steam power plant system is held as follows.

In the KBRT system, there is only one controlled variable, the steam pressure of the boiler, so it is univariate control. While in the risk-based SPC system, there are three controlled 
varubles. ie, the seam flow rate, the stcam pressure and the stcam tanperature of the boiler, so it is maltivariate control.

In the KBRT wysem, to prodace falt in the steam pressure of the boiler, Unafe Boiler Prevere butue is specially set in the cansole wo chain bigh valie unofle stcam pecaure, as shown in Fiz. 55. Uning the Unsufe Boiler Presure bunva, the obeained steam

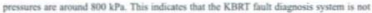
sensitive to fault event, and only with bigh values that the KBRT system can identify the fatl and then take action(s). On the other hand, the maximum provore fer the boiler is $690 \mathrm{KP}$, so these high values would destroy the boiler and steam power plant system. Whereas, the risk-tased SPC frelt diagnosis syiem is an accurate and scnsitive diagnosis approuch It cas capture any fault coent according to the

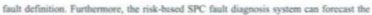
fall and tuke actioe(s) in adrance.

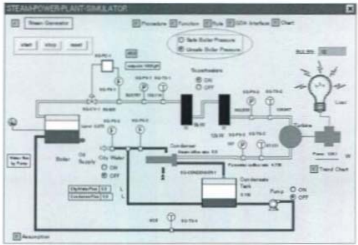

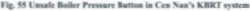


In the KBRT system, the outputs of FDD and SDD depend on the most recent five diserete input data, so the quality of those data could affect the accuracy of identification. This primitive identification approach ereates an instantaneous recognition and the result cannot be changed later. Besides, in order to obtain accurate and reasonable results, the membership functions used in the analysis to the system output have to be adjusted for different fault events every time. In risk-based SPC system, the original real time data are directly used as the input to the fault diagnosis system, and the output of the fault diagnosis system are the exact data. In this way, we can avoid input dependency, and assure the accuracy in system output. Besides, since both input and output are exact data, the corresponding risk assessment to the system are also exact results.

In the KBRT system, noise is a major problem in primitive identifieation. There is no noise canceling technique used in this primitive identification approach. The input sensor data need to be filtered before performing any analysis. While in risk-based SPC system, moving average technique is used to eliminate the noise disturbance.

In the KBRT system, due to the uneertain characteristic of primitive identification and the similar shape between some primitives, it is impossible to perform an exact comparison, so Cen Nan introduced SI to decide the degree of approximation to do the trend analysis. While in risk-based SPC system, all the input, output and risk assessment are exact data or results.

In the KBRT system, to quantify the temporal pattern of sensor data, Cen Nan introduced another variable ROC to act as an input to the fault diagnosis system. Besides, in G2 environment, one fuzry evidence gate only allows three combined if-then rules, therefore, if more rules are used, like in the KBRT fault diagnosis system, repeated or redundant components are used. In risk-based SPC system, redundancy avoiding design makes the system more compact. 
In the KBRT system, the developed application can only be effective to the studied system (Cen ete, 2008). This means the methodology developed by Cen Nan is not good in extensibility. While the risk-based SPC system has excellent extensibility, not only it can be applied in the studied systems, the tank filling system and the steam power system, but also can be popularized to other industrial processes. Furthermore, after modification, it can be extended to be applied in the real time monitering and prediction to natural catastrophes, such as tsunami, earthquake, etc, and even in economic analysis.

The comparison between the KBRT approach and the risk-based SPC approach for the steam power plant system is shown in Table 10.

Table 10: Cernparisen betwern the KBRT Approach and the Kisk-based SPC Appreach

\begin{tabular}{|l|c|c|}
\hline \multicolumn{1}{|c|}{ Characteristics } & KBRT approach & Risk-based SPC approach \\
\hline Controlled Variable & Univariate & Multivariate \\
\hline BPCS & Yes & Yes \\
\hline SIS1 & No & Yes \\
\hline SIS2 & No & Yes \\
\hline Real Tume Monitoring & Yes & Yes \\
\hline Forecast Capability & No & Yes \\
\hline Risk-based Development & No & Yes \\
\hline Noise Filtering & Yes & Yes \\
\hline Additional Hardware for & Yes & No \\
\hline Noise Filtering & & 3 \\
\hline SIL & 2 & Yes \\
\hline Independency & No & No \\
\hline Redundancy & Yes & Excellent \\
\hline Adaptability & Not Good & Excellent \\
\hline Sensitivity to Fault & Not Good & Excellent \\
\hline Extensibility & Not Good & \\
\hline
\end{tabular}




\section{Chapter 5 Characteristics of the Proposed Methodology}

From the verifications and descriptions of the tank filling system in Chapter 3 and the steam power plant system in Chapter 4, we can see that the proposed methodology of risk-based SPC fault diagnosis and its integration with safery instrumented systems has the following characteristies:

\section{Adaptability}

In the fault diagnosis and safety management to process systems, data analysis to the industrial processes data is indispensable. Statistics is a mathematical science pertaining to the collection, analysis, interpretation or explanation, and presentation of data (Moses etc., 1986). From the previous sentence, we can see that Statisties exists for data analysis. In the proposed methodology, statistical techniques like control chart, moving averages and time series are used to do data analysis to the real time monitored process data. Since Statistics is applicable to a wide variety of academic disciplines, including natural and social scienees, government, and business; the proposed methodology will have excellent adaptability to all kinds of industrial processes, and also to other various scientific technology fields.

\section{Real-time Monitoring Capability}

In the developed systems using the proposed methodology, real time monitoring to the controlled variable(s) is conducted, and both the inputs to the system and the outputs of the system are exact real time data. Using control chart and trend chart techniques, the outcome can be visually observed and monitored in real time, any fault or abnormal situation can not escape to be captured promptly. 


\section{Forecast Capability}

Forecast capability is essential to a fault diagnosis and safety munagement system. Due to the use of time series and linear trend analysis techniques, the proposed methodology has excellent fault forceast capability to the real time data, and it can perform the best linear trend forecast to the process controlled variables with $G 2$ software. This is very helpful for us to take corresponding actions in advance.

\section{Effectiveness and Strong Safety Management Capability}

The risk-based fault diagnosis and safety management system is effective both in fault diagnosis and in safety management to the process system. It can capture any fault event according to the fault definition. Furthermore, the risk-based SPC fault diagnosis and safety management system can forecast the fault and take action(s) in advance. This capability helps us to make precaution before faults happen and also offset the effect afler faults have happened. After implementing SIS1 and SIS2 to the developed systems, the SIL of the developed systems has upgraded from SIL.2 to SIL.3.

\section{Independeney}

Unlike in the KBRT system, the outputs of FDD and SDD depend on the most recent five discrete input data, and in order to obtain reasonable results, the membership functions used to analyze the system output have to be adjusted for different fault events every time. In risk-based SPC system, the original real time data are directly used as the input to the fault diagnosis system, and the output of the fault diagnosis system are the exact data. In this way, we can avoid input dependency, and assure the accuracy in system output.

\section{Robust Capability}

Moving average technique is commonly used with time series data to smooth out 
short-term fluctuations and highlight long-term trends. Mathematically, a moving average is also similar to the low-pass filter used in signal processing. In the developed risk-based SPC fuult diagnosis and safety management systems, moving average technique is used to filter out noise from the real time data. This increases the system robust capability.

\section{Transplantable Capability}

Considering the transplantable capability for the developed system, standardization and modularization designs are used in the development. Thereby, program ean be transplanted from one system to another easily. This inereased the flexibility of system development.

\section{Reasonability in System Design}

Considering the possible future application in practice, some functions are implemented in the software, i.e., in the programs. This eapability decreased the number of hardware components in system, and correspondingly reduced the size of system and the cost for development and implementation in practice.

\section{Extensibility}

The risk-based SPC system has excellent extensibility, not only it can be applied in the studied systems, the tank filling system and the steam power system, but also it can be popularized to other industrial processes. Furthermore, after modification, it can be extended to be applied in the real time monitoring and prediction to natural catastrophes, such as tsunami, earthquake, etc. and even in ceonomic analysis.

\section{Multiple Fault Identifiable Capability}

The ability to identify multiple faults is an important but a difficult requirement 
(Venkatasubramanian et al, 2003). In the risked-based SPC fault diagnosis and safety management system, multiple faults identification has been completed successfully. The breakthrough from univariate monitoring to multivariate monitoring for SPC fault diagnosis has been made in this research, and also the correlation problem among the multiple controlled variables has been solved. 


\section{Chapter 6 Conclusion and Future Work}

\subsection{Conclusion}

There are abundant literatures on process fault diagnosis approaches which range from analytical redundancy to knowledge-based systems and neural networks. Broadly, the existing process fault diagnosis approaches can be classified into three general categories. They are quantitative model-based methods, qualitative model-based methods, and process history based methods. Quantitative model-based method is impractical to be utilized in real industrial processes because of system complexity, high dimensionality and process nonlinearity. Qualitative model-based method will generate spurious solutions when reasoning with qualitative models. While the conventional process history-based method needs large amount of historical process data. For these above reasons, Venkatasubramanian et al. (2003) even propose to develop hybrid systems to overcome the limitations of individual approach. In this situation for fault diagnosis in process engineering and the safety incidents that lead to the serious consequences for people, the environment and property, an innovative methodology of risk-based SPC fault diagnosis and its integration with Safety Instrumented System (SIS) for process systems is proposed in this research.

The proposed methodology of risk-based SPC fault diagnosis and safety management neither depends on the process models as model-based methods, nor depends on large amount of historical process data as conventional process history based method. Earlier developed control charts are used to distinguish abnormal situation from normal operation based on three-sigma rule and linear trend forecast. To minimize the number of false alarms, risk indicators are used to identify and determine potential fault(s).

In order to testify the proposed methodology, two process systems are built in G2 
development environment. The first process system is a tank filling system in process industry, and the second process system is a steam power plant system located in Thermodynamies and Fluids Lab in Faculty of Engineering and Applied Science building at Memorial University of Newfoundland.

Through the verifieation of the proposed methodology in the tank filling system in Chapter 3, we can see that all the thresholds, including the maximum volume for the tank, were designated by the designer, and no model is needed in the fault diagnosis and safety management process. Therefore, the fact that the proposed methodology neither depends ou any model, nor depends on large historical data has been verified. Further, through the comparison between the tank filling system developed with the proposed methodology and a traditional design for the same system from the previous developer Cen Nan, we can conclude the advantages of the former system over the latter system as shown in Table 9 .

Through the verification of the proposed risk-based SPC fault diagnosis and safety management methodology in the steam power plant system in Chapter 4, we can see that the proposed methodology neither depends on any model, nor depends on large historical data, because in the steam power plant system, we just need to know the nomal operation values and the extreme limits for the component parameters, while these nomal operation values and the extreme limits are just like the nominal values and specification limits for a component, such as a capacitor or a breaker in a circuit. Above all, in this verification, a breakthrough has been made, that is, the breakthrough from univariate monitoring to multivariate monitoring for SPC fault diagnosis, and also the correlation problem among the multiple controlled variables has been solved. Further, through the comparison between the steam power plant system developed with the proposed methodology and the traditional expert systems method for the same system, we can conclude the advantages of the former system over the latter system as shown in Table 10.

From the verifications and deseriptions of the tank filling system in Chapter 3 and the 
stearn power plant system in Chapter 4, it can be coocluded that the proposed methodolegy of risk-based SPC fault diagnosis and is integration with safery instramented systems has 10 outstanding characteristics, ruch as Aceuracy, Real-time Monitoring Capability, Forecast Capabiliry, ete, as deseribed in Chapter 5 . With these to outstanding characteristics, this proposed methodology is desired to be the ideal solution for the fault diagnosis and safery management in the process crgineering

In summary, the main conclusions for this research ane as follows

- An innovative methodology of risk-hased SPC fault diagnosis and its integration with StS for process wystems has been proposed.

- The proposed methodology has been verified through two process systems that it neither depends on any model as nodel-based approuches, nor depends on large amount ef historical data as conventianal process history based methods

- A technique becakthroagh, from univariate monihoring to maltivariate monitoring for SPC fult diagnosis, has been achieved in this revearch.

- The advantages of the proponed methodology over Cen Nan's wark for Tank Filling System are summarined in Table 9.

- The advantages of the proposed methodology over inifitional expert system for Seam Power Plant Sysecm are summariad in Table 10

- 10 eutstanding characteristies of the proposed methodology are listed in Chapter 5. 


\subsection{Future Work}

Introduced into the process fault diagnosis in 1931 as the Shewhart control chart, the conventional SPC charts have been extensively used in industrial processes. However, the conventional SPC fault diagnosis method is not written into any branch in Fig. 13, because there are two vital limitations for the conventional SPC fault diagnosis method. One is that the conventional SPC chart is a univariate control chart, and it can not handle multivariate processes and the correlation among controlled variables. The other vital limitation for the conventional SPC method is in the data acquisition technology.

In this research, the first limitation has been solved, that is, the breakthrough from univariate monitoring to multivariate monitoring for SPC fault diagnosis has been made, and also the correlation problem among the multiple controlled variables has been solved. So, the future works for this research are as follows:

1. Further develop the multivariate monitoring for the proposed methodology of risk-based SPC fault diagnosis and its integration with safety instrumented system (SIS).

2. Try to realize another breakthrough for the other limitation of the SPC fault diagnosis in the data acquisition technology.

3. Apply the proposed methodology which has broken through the two limitations into real process systems. 


\section{References:}

Albazzaz, H. and Wang, Z. X. (2004). Statistical process control charts for batch operations based on independent component analysis. Ind. Eng. Chem. Res., 43, $6731-6741$

Bowling, R. S., Khasawnch, T. M., Kacwkuckool, S. and Che, B. R. (2009). A logistic approximation to the cumulative normal distribution. Jotumal of Industrial Engineering and Management, 2(1), 2013-0953.

Chang, S. Y, and Chang, C. T. (2003). A fuzzy-logic based fault diagnosis strategy for process control loops. Chemical Engincering Science, 58, 3395-3411.

Chen, A. and Elsayed, E. A. (2000). An alternative mean estimator for processes monitored by SPC charts, International Journal of Production Research, 38(13), 3093. 3109.

Crow1, D. A. and Louvar, J. F. (2002). Chemical Process Safery Fundamentals with Applicarions(2nd ed.). New Jersey: Prentice Hall PTR.

Fawcet, H. H. and Wood, W. S.(1982). Safety and Accident Prevention in Chemical Operations (2nd ed.). New York: Wiley.

Flott, W. L. (2002), What is SPC? Metal Finishing, 100(2), 112-114.

Ghetic, M., Noura, H. and Saif, M. (1998). Fault diagnosis using balance equations methods and the algorithmic redundancy approach. Proceedings of the 37th IEEE Conference on Decision \& Control. Tampa, Florida USA.

Ghodrati, B., Akersten, P. and Kumar, U. (2007). Spare parts estimation and risk 
assessment conducted at Choghart Iron Ore Mine: A case study. Joumal of Qualiny in Maintenance Engineering. 13(4), 353-363.

Guhhn, P (1999), Safety Instrumented System Design: Lessons Leamed, Process Saffery Progress, 18 (2), 156-160.

Harms-Ringdahl, L. (2001). Safery Andysir - Principles and Practice in Occapational Safety (2nd ed.) Taylor \& Francis, London.

Harms-Ringdahl L. (2009). Analysis of safefy functions and barriers in accidents. Safen Science, $47,353-363$.

He, T, Xie, W, Wu, Q and Shi, T. (2006). Process fault detection and diagnosis based on prineipal component analysis. Proceedings of the Fifth International Conference on Machine Learning and Cybernetics, Dalian, China.

Himmelblau, D. M. (1978). Fauli detection and diagnosis in chemical and pernochemical processes. Amsterdam: Elsevier press.

IEC (International Electrotechnical Commission), (2001). Functional Safety of Electrical/Electronic/Programmable Electronic Safety-Related Systems (Standard IEC 61508), IEC, Geneva.

Jin, N. and Zhou, S, (2006). Signature constraction and matching for fault diagnosis in manufacturing processes through fault space analysis. IIE Thansactions, 38, 341 - 354

Khan, 1. F., Sadiq, R., and Husain, I. (2002). Risk-based process safety assessment and control measures design for offshore process facilities. Jowrnal of Hazandous Materials, A $94,1-36$ 
Kirkwood, D. and Tibbs, B. (2005). Developments in SIL determination. Computing and Control Engineering, 16(3), pp 21-27.

Knegtering, B. and Pasman, H.J. (2009). Safety of the process industries in the 21st century: A changing need of process safety management for a changing industry. Journal of Lass Prevention in the Process Induxtries, 19, 298-305.

Leonard, A. D. (1996), Statistical Process Control (2nd Ed.). New York, NY: Industrial Press Inc.

Lo, C. H., Wong, Y. K. and Rad, A. B. (2004). Model-based fault diagnosis in continuous dynamic systems. IS.4 Thansactions, 43, 459-475.

Lo, C. H., Wong, Y. K. and Rad, A. B. (2006), Intelligent System for Process Supervision and Fault Diaenosis in Dynamic Physical Systems. IEEE transactions on industrial electronics, 53(2), 581-592.

Lundteigen, A. M. and Rausand, M. (2007), Common cause failures in safety instrumented systems on oil and gas installations: Implementing defense measures through function testing. Journal of Loss Prevention in the Process Industries, 20, 218 $-229$

Ma, C., Gu, X. and Wang, Y (2009). Fault diagnosis of power electronic system based on fault gradation and neural network group. Nenrocamputing, 72, 2909 - 2914.

MacDonald, D. (2004). Practical Industrial Safety, Risk Assessment and Shutdown Systems for Industry. New York: Newnes.

Marszal, Edward M., \& Mitehell, Kevin 1. (2003). Defining Safety Instrumented Functions. Safety Instrumented Systems for the Process Indastry Confenence, 1-16. 
Maurya, R. M., Rengaswamy, R. and Venkatasubramanian, V. (2004). Application of signed digraphs-based analysis for fault diagnosis of chemical process flowsheets. Engineering Applications of Artificial Intelligence, 17, 501 - 518 .

Mohamed, L. and Tbrahim, A. S. (2002). Model-Based Fault Diagnosis via Parameter Estimation Using Knowledge Base and Fuzzy logic Approach. IEEE melecon, Cairo, EGYPT.

Moses, L. E. (1986). Think and Explain with statistics, Addison-Wesley.

Nan, C. Khan, F, and Iqbal, M. T. (2008). Real-time fault daagnosis using knowledge-based expert system, Process Safery and Eminonmental Protection, 86(1 B), 55.71 .

Nemeth, E. Lakner, R. Hangos, K.M. and Cameron, I.T. (2007). Prediction-based diagnosis and loss prevention using qualitative multi-scale models. Information Sciences, $177,1916-1930$.

Ogata ,K. (2004). Modern Control Engineering. Upper Saddle River, N.J.: Preatice Hall

Ong, H. K., Harvey, M. C., Shehab, L. R., Dechert, D. I. and Darisipudi, A. (2004). The effects of three statistical control charts on task performance. Production Planning of Control, 15(3), $313-323$.

Orantes, A., Kermpowsky, Lann, L. T. M.-V., and Aguilar-Martin, J, (2008). A new support methodology for the placement of sensors used for fault detection and fiagnosis, Chemical Engineering and Processing, 47, 330 - 348 
Pham H. (2006), Springer Handbook of Engineering Slatistics. New York: Springer.

Simani, S, and Fanturzi, C. (2000). Fault diagnosis in power plant using neural networks. Information Sciences, 127, 125-136.

Singer, G and Ben-Gal, 1. (2007). The Funnel Experiment: The Markov-based SPC Approach. Wiley InterScience, $899-913$,

Stavrianidis, P. and Bhimavarapu, K. (1998). Safety instrumented functions and safety inteyrity levels (SIL), ISA Thansactions, 37, 337-351.

Summers, E. A. (2007). Safety Instrumented Systems, Perry's Handbook of Chemical Engineering (Fall ed.)

Venkatasubramanian, V., Rengaswamy, R. and Kavuri N. S. (2003). A review of process fault detection and diagnosis Part II: Quanlitative models and search strategies. Computers and Chemical Engineering, 27, 313-326.

Venkatasubramanian, V., Rengaswamy, R., Kavuri, N. S. and Yin, K. (2003). A review of process fault detection and diagnosis Part III: Process history based methods. Computers and Chemical Engineering, 27, 327-346

Venkatasubramanian, V., Rengaswamy, R., Yin, K. and Kavuri, N. S. (2003). A review of process fault detection and diagnosis Part 1: Quantitative model-based methods. Computers and Chemical Engineering, 27, 293-311.

Wheeler, D. J., \& Chambers, D.S. (1992). Understanding Statisficat Process Control (2nd Ed.). Knoxville, TN: SPC Press.

Wiegerinck, Jan A. M. (2002), Introduction to the Risk based design of Safety 
Instrumented Systems for the process industry. Seventh International Confenence on Control, Automation, Robotics And Vision, 1383-1391.

Zhang, J. (2006). Improved on-line process fault diagnosis through information fusion in multiple neural networks. Computers and Chemical Engineering, 30, 558-571. 


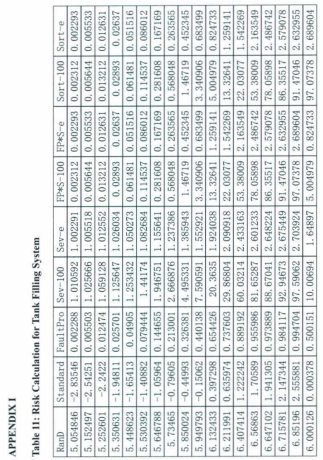




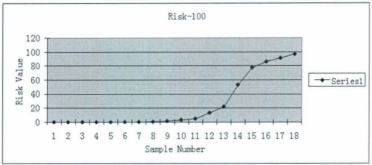

Fig. 56 Rish Value vs Sample Number Graph with Base 100

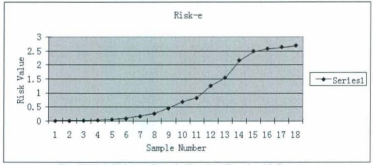

Fig. 57 Risk Value vs Sample Number Graph with Base e 


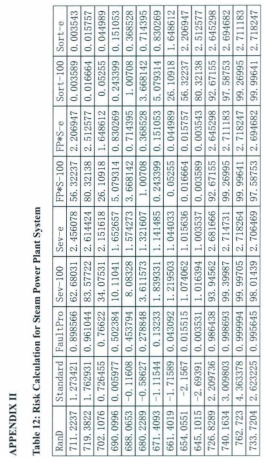




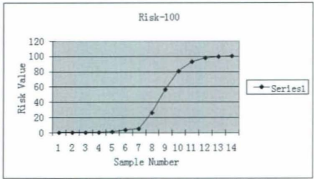

Fig. 58 Risk Value vs Sample Number Graph with Base 100

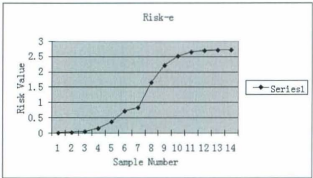

Fig. 59 Risk Value vs Sample Number Graph with Base e 


